\title{
ARTICLE
}

Cite this: DOI: $10.1039 /$ xoxxooooox

Received ooth May 2014,

Accepted ooth

DOI: $10.1039 /$ xoxxooooox

www.rsc.org/

\section{Post-Blast Explosive Residue - A Review of Formation and Dispersion Theories and Experimental Research}

\author{
N. Abdul-Karim ${ }^{a, b}$, C. S. Blackman ${ }^{a}$, P. P. Gill ${ }^{c}$, E. M. Wingstedt ${ }^{d .} \&$ B. A. P. \\ Reif $^{d}$.
}

The presence of undetonated explosive residues following high order detonations is not uncommon, however the mechanism of their formation, or survival, is unknown. The existence of these residues impacts on various scenarios, for example their detection at a bomb scene allows for the identification of the explosive charge used, whilst their persistence during industrial explosions can affect the safety and environmental remediation efforts at these sites. This review article outlines the theoretical constructs regarding the formation of explosive residues during detonation and their subsequent dispersal and deposition in the surrounding media. This includes the chemical and physical aspects of detonation and how they could allow for undetonated particles to remain. The experimental and computational research conducted to date is presented and compared to the theory in order to provide a holistic review of the phenomenon.

\section{Introduction}

The term 'explosive residue' here refers to the undetonated submicroscopic particles ${ }^{1}$ which remain following an explosion as opposed to the partially reacted or decomposition products of the original explosive material. In forensic contexts the products formed from an explosive are usually vapours and inorganic salts of limited diagnostic value $\mathrm{e}^{2,3}$ and therefore it is the undetonated material which provides invaluable chemical signatures at post-blast bomb scenes. The main aim of bomb scene investigation is to establish the cause of and responsibility for the incident as soon as possible; when relying only on the scene for information one of the primary methods to do this is collecting explosive residue. Trace explosive residues have high evidentiary value as they can provide information about the chemical composition of the explosive material, and thereby indicate whether it was commercially available or homemade, domestic or foreign material, or associated with a particular terrorist or criminal organisation ${ }^{4}$. It is also becoming increasingly important to identify this residual material in situ, from samples taken from fixed areas at the scene rather than that adhered to portable objects, in order to offer evidence in court that the material was found at the scene and not placed there after the event. Experience has led to the practice of focusing the collection of explosive residues from items based on their proximity to the centre of the explosion, but no rigid rules are in place ${ }^{2,5}$. Sometimes surfaces or objects display visual signs of having been close to the explosion such as cratering or pitting damage, and these may yield residue. However if no visible signs of damage are present this does not negate the possibility of recovering residue from a particular item as explosions can leave imperceptible traces of explosive residue $^{6,7}$. The issue therefore is to know where to look for it. Whilst residue sample collection and analysis procedures have been widely researched in the open literature, the scientific basis of where to locate explosive residues has not yet been established. The importance of locating explosive residue is reflected in current forensic texts and guidelines, with some stating it is the most important $\operatorname{task}^{8}$ because these explosive particles are one of the first things to be analysed in the laboratory ${ }^{9}$, and even noting that the "key to success lies primarily with the collection of residues at the scene of an explosion" (pg. 108) ${ }^{1}$. However very few texts expand further on how to do so, with comment only on the fact that residues are present ${ }^{10-12}$ and do scatter ${ }^{13}$ without detailing where they may scatter.

In an industrial setting it is the unreacted particles which can compromise health and safety at blasting sites $<$ sup $>14</$ sup $>$ and during military testing the persistence of these particles and their subsequent leaching into groundwater impacts the environmental remediation efforts required to ensure effective clean-up procedures have been maintained at training grounds ${ }^{14}$. Research into the production of 'green' explosives which minimize the environmental and health risks posed by detonation residues is being conducted ${ }^{15,16}$, however the options are not currently economically viable and therefore it is becoming more important to understand the distribution of undetonated residues in order to mitigate their negative impact ${ }^{14}$. 
The undetonated residues which can be found following detonation do not always resemble the original explosive crystals exactly but can be representative of the explosive. It is also possible for the residues to have undergone morphological changes and appear as spherical particles, formed upon cooling of molten ejected explosive ${ }^{17}$. During an explosion event the survival of particles which have not been consumed or partly reacted may seem counterintuitive due to the high pressures and temperatures involved in the reactions, and yet it is not uncommon for them to be found ${ }^{14,18}$. However, the mechanisms of formation, or indeed survival, of undetonated explosive residues are not fully understood although there is a theoretical basis for their existence. In order to provide a full account of these, first the chemical and physical aspects of an explosion are briefly outlined.

\section{Chemical and Physical Aspects of Explosion}

Chemical explosions are a result of rapid chemical reactions driven by large exothermic and positive entropy changes in going from reactants to products ${ }^{19}$. On ignition of a chemical explosive by an external stimulus (friction, heat, shock, etc.) the energy input will cause the temperature of the explosive to rise as the stimulus energy is converted to heat to produce localised regions called hotspots. Mechanisms for hotspot formation include adiabatic compression of small entrapped bubbles of gas in the explosive, friction caused between sliding surfaces such as grit particles or explosive crystals, or cavity collapse of the surrounding matrix material ${ }^{19-21}$. If there is sufficient energy increase in the hotspots heat will be transmitted and reactions will develop ${ }^{20}$. During the thermal decomposition of the reactants the atoms of the explosive molecules separate, and due to the energetic stability of the gaseous product, form strongly bonded species such as carbon monoxide, carbon dioxide and di-nitrogen gas. The products formed depend on the quantity of oxidising atoms present in the original molecule $\mathrm{e}^{19,22}$.

If rapid burning occurs, with the reacted material moving away from the unreacted material at a subsonic speed, the explosive can undergo deflagration. The propagation of explosion during deflagration is based on energy transfer via thermal reactions and is relatively slow. The decomposition of newly exposed surfaces during the reactions is less likely to be completely efficient and deflagrating explosives are therefore more likely to produce undetonated residues ${ }^{23}$.

If the reactions propagate supersonically the explosion is termed a detonation; low-order detonation if the rate is below the maximum detonation velocity possible for the explosive and high order detonation if the rate is at the explosives highest possible velocity (which can be over $8000 \mathrm{~m} \mathrm{~s}^{-1}$ ). The decomposition of the explosive during detonation occurs due to a shockwave. The pressures generated within the primary reaction zone increase the speed of the reaction, thus increasing the pressure in the reacting material which in turn produces a detonation wave ${ }^{19,24}$. The detonation wave has regions of compression and rarefaction, and is led by a shock front progressing at a constant velocity into the unreacted material and is sustained by the decomposition of the explosive material behind it.
The velocity of detonation (VOD) is the speed at which the shock front travels through the detonated explosive and is affected by the type of explosive material, its density and diameter. Generally, as the density of the material increases so does the VOD, particularly for homogenous explosives, and the material has to be at or above a critical diameter (characteristic of each explosive) for the wave front to be sustained and move through the explosive charge $\mathrm{e}^{19,25-27}$.

On reaching the periphery of the explosive the shockwave passes into the surrounding medium and exerts a sudden and intense pressure upon it, forming craters on the ground, bubbles in water, and blast waves in $\operatorname{air}^{25}$. The brisance, or shattering effect, of the explosive is determined by this detonation pressure. A shock wave in air would also have a blast wave associated with it at the front of the shock. The initial blast wave velocity is high, but the shock decays with distance to the speed of sound in air and the blast wave undergoes systematic changes in amplitude, duration and profile. After a rapid rise in pressure followed by decay, there is a negative duration where the pressure is below atmospheric level due to the inertial effect caused by the initial outward movement of air. Air then rushes back in to this 'void' and returns to ambient pressure ${ }^{25}$. A typical profile (Friedlander waveform) is shown in figure 1.

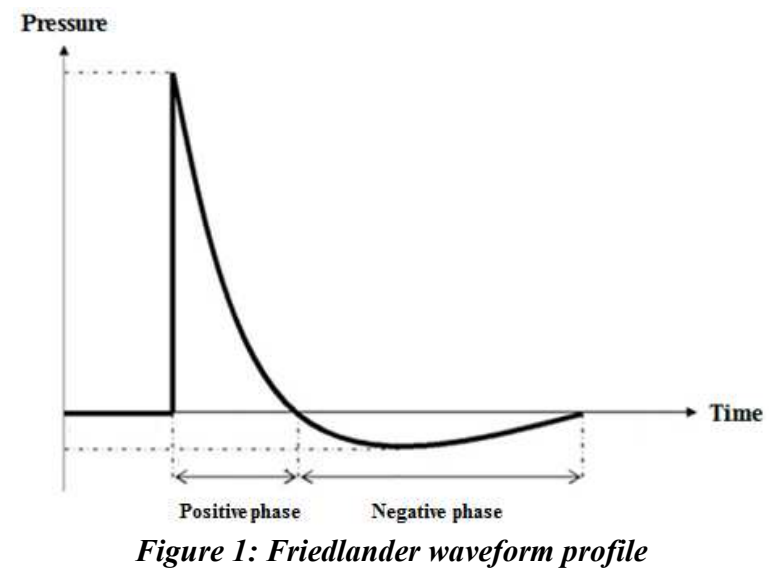

It would seem counter intuitive to expect undecomposed particles during high explosive detonations to remain intact where the pressure can reach $100 \mathrm{GPa}$ and temperatures over $5000 \mathrm{~K}^{28}$. Yet undetonated particles are often found following detonation ${ }^{14}$.

\section{Explosive Residue Formation}

The most recognisable undetonated explosive material at a post-blast scene is usually that remaining following a partial detonation, which could be caused by a failure in the booster charge or detonator or some inhomogeneity in the main charge ${ }^{18}$. Partial detonations leave undetonated residues in the form of large deposits that are easier to identify. Nevertheless, even when a full or complete detonation has occurred undetonated explosive residues are still found ${ }^{3}$ due to incomplete combustion, even to some minor degree, of the explosive. The reason for the inefficiency of the combustion process is unknown to date, however it has been theorised that when the shock front passes from the periphery of the explosive into the surrounding medium the shock wave can be partially reflected at this 
discontinuity $^{27}$, and hence the surface layers of the charge may not react completely ${ }^{18}$. It is from this area on the outer layer of the charge that undetonated explosive residues are hypothesised to survive. However, the exact details of how this may occur and why a reflection of the shockwave at this interface would limit reaction are not explained. Nonetheless, if this theory is correct and undetonated residues do survive in this way the amount of undetonated material remaining following a detonation would vary depending on a number of factors including the charge mass, diameter, VOD and number of interfaces within the charge ${ }^{18}$. Larger charge masses would produce less undetonated residues relative to smaller ones because the amount of residue would be proportional to the surface area of the charge and the greater the charge mass the less surface area it would have relative to its volume $\mathrm{e}^{3}$ thus producing relatively fewer undetonated residues. Furthermore, as the charge diameter increases the velocity of detonation increases up to a limiting point ${ }^{29}$ thereby decreasing the size of the reaction zone and narrowing the interaction zone at the explosive-air boundary layer where unreacted material may survive ${ }^{17,18}$. Larger reaction zones are less likely to release chemical energy at a rate needed to exceed that which can sustain the wave and therefore explosives with higher VODs produce less undetonated residues; for example fewer residues remain following the detonation of 1,3,5-Trinitroperhydro-1,3,5triazine (RDX) (VOD; $\left.\sim 8440 \mathrm{~m} \mathrm{~s}^{-1}\right)^{19}$ compared to ammonium nitrate (AN) (VOD; $\left.\sim 5000 \mathrm{~m} \mathrm{~s}^{-1}\right)^{30}$.

Despite the outlined hypotheses, no empirical evidence has been published which tests the theories for the formation of trace undetonated explosive residues from apparently complete or full detonations against the nature of the charge or the surface/area ratios. In order to better understand where to locate undetonated particles it is necessary to first of all understand the way in which they are produced. Despite the lack of experimentally supported knowledge in this area, two distinct methods for the dispersal of undetonated particles are apparent; those which are adhered to fragments of the explosive device, such as the casing, and those which move freely, i.e. unattached to any other material. The dispersal mechanisms for each type of distribution will vary and are discussed below.

\section{Explosive Residue Distribution}

\section{Fragment Based Dispersion Theory}

The distribution of undetonated material adhered to fragments depends on the fragment movement. When the forces acting on any material used to contain an explosive exceed the holding strength of that confining material, the stress and resulting strain upon it will cause it to fragment and these fragments will be ejected. It has been experimentally determined that the initial velocity of a metal fragment can be related to the mass of the explosive and the mass of the metal casing ${ }^{31,32}$. Velocities of fragments have been found to be specific to each explosive material and have been derived by modelling energy distribution between metal shells and detonation gases for different explosives ${ }^{26,33}$. From this work a series of equations (Gurney equations) were derived for solid casings with simple geometries ${ }^{32,33}$. With the use of these equations and their development, it has been suggested that the distribution of fragments may be based on the inverse square law $^{34}$, i.e. the quantity of material found would be inversely proportional to the square of the distance from the detonation centre. The distance travelled by a fragment has also been investigated elsewhere and found to be dependent on its size, shape, weight, material, angle of trajectory and any resistant forces working upon $\mathrm{it}^{35}$.

The maximum distances $\left(R_{\max }\right)$ moved by fragments have been predicted for different metals $^{36}$, where the relationship between distance and fragment was determined to be only a function of fragment density and maximum fragment mass ${ }^{36}$. Based on the results of this work, equation 1 was stated in another report ${ }^{18}$ to relate the fragment density, $\mathrm{r}\left(\mathrm{g} / \mathrm{cm}^{3}\right)$, and the maximum fragment mass, $\mathrm{w}(\mathrm{kg})$, to the maximum fragment range, $\mathrm{R}_{\max }$. In contrast to the Gurney equations the relationship does not take into account the effect of the explosive type or explosive mass.

$$
\mathrm{R}_{\max }=190 \mathrm{r}^{-.112} \mathrm{~W}+52 \mathrm{r}^{858}
$$

Equation 1 fits well with results from computer models ${ }^{37}$ of fragment distribution with fragment densities of $0.8-1.2 \mathrm{~g} / \mathrm{cm}^{3}$, however these computations were based on the detonations of gas, liquid and vapour clouds rather than solid explosives and so may not be wholly applicable to condensed explosive charges. Nonetheless, the equation may be able indicate the movement of free-moving undetonated residues (those which are not adhered to any casing fragments). Based on equation 1 , if the mass of the fragment decreases, a limiting value of $52 \mathrm{r}^{.858}$, and therefore of approximately 60 metres, remains ${ }^{18}$. This could hypothetically be applied to estimate the distance moved by undetonated residue 'fragments'. Whist equation 1 is said to fit the computational experiments ${ }^{37}$ and is based on data from the fragment range experiments ${ }^{36}$, it's derivation from the actual data is not provided in the report in which it is presented $^{18}$ and cannot therefore be theoretically justified.

Whilst the inverse square law and a hypothetical radii of 60 metres within which fragments may be found provides a basis for the theory of fragmentation distribution, little experimental work has been produced to fully support either the law or the estimated radii. Theoretical studies and experimental work has assessed the distribution of mass amongst collected fragments but has not assessed their spatial distribution ${ }^{38-42}$ and so are not discussed here. Furthermore, stages of the detonation process that could affect the distribution of fragments are not considered in the theories. These include factors such as the detonation wave which may accelerate the fragments or the blast wind which may impact on the movement of fragments, as well as the negative phase of the pressure pulse described earlier which could cause lighter fragments to be drawn back toward the detonation centre rather than propelled outwards. Clearly some evidence base exists from which the distribution of undetonated explosive residues can be derived if it is assumed that they are adhered to fragments of an encasing material. However not all fragments may contain traces of undetonated particles, hence why it is necessary to understand the method by which these particles move independently or freely of encasing material during detonation. 


\section{Explosive Residue Distribution}

\section{'Free Moving' Particle Dispersion Theory}

The movement of explosive residue outwards from the detonation centre has been hypothesised as being due to the positive and negative blast pressures pushing and impeding particles ${ }^{3,18}$. It has been proposed that undetonated residues (from confined or unconfined charges) would move at the same speed away from the charge irrespective of the composition of the main charge ${ }^{18}$. The particle velocity at the charge surface would be a function of the speed of sound in the unreacted explosive ${ }^{26}$ and as this does not vary widely over a range of common explosives, would be a similar amount across different explosive charge types. The velocity of the particles does not however explain their complete trajectory. Others consider the residue deposition to occur primarily due to the smoke cloud formed following the decay of the fireball (which assumes unreacted particles exist within it), the movement of which is governed mostly by the wind direction, and not the initial shock wave or pressures formed during the detonation ${ }^{43}$. Whilst either stage of detonation, the blast wave or the smoke plume, could be the principal dispersal mechanism, it is not implausible that both have an effect on the particle movement.

One text explains that undetonated residues which survive the explosion may be physically dispersed by the shockwave ${ }^{3}$ and factors that would affect the subsequent location of these undetonated residues are listed as: the concentration of the original explosive material; the fireball; the nature of the surface; and the orientation of the surface ${ }^{3}$.

1) The concentration of the original explosive material: approximations could be made that residues are equally distributed and spread over the surface of a sphere. The amount, c, in grams of material on $1 \mathrm{~cm}^{2}$ of a surface is said to be determined by equation $2^{3}$ :

$$
c=\frac{\left(10^{-4} W\right)}{\left(4 \pi r^{2}\right)}
$$

Where $\mathrm{W}$ is the total mass of distribution material in grams and $\mathrm{r}$ is the distance from the charge in metres. The amount per unit area will decrease proportionally to the reciprocal of the square of the distance from the charge (inverse square law). Based on this, it has been suggested that the distance at which concentrations will be lower than detection limits is relatively short and so undetonated residues would be found close to the explosion seat or centre ${ }^{3}$. Whilst indicating a generic trend of residue distribution, the equation would not necessarily satisfy the dispersal from non-spherical explosive charges. Moreover, equation 2 may apply for a perfect unconfined spherical system, where no other variables such as the surrounding wind speed or direction are encountered, however in reality this is almost always not the case.

With regards to the detection of low concentrations it must be noted that the actual quantities of undetonated explosive residues recovered from samples collected following high order detonations are detected at the part-per-billion (ppb) or part-per-million (ppm) range, with the detected concentrations dependent on the collection method and analytical techniques employed. If prior knowledge of the exact explosive material detonated is unavailable, initial laboratory screening methods must be selective for a range of explosive analytes. The limits of detection (LOD) for various analytical techniques depend on their sensitivity to these individual explosive analytes. Chromatographic techniques are laboratory stalwarts for the detection of trace explosives; however the LOD depends on the detector used. With gas chromatography for example, electron capture detectors (ECD) have been used to detect less than $1 \mu \mathrm{g} / \mathrm{kg}$ of explosives such as 2,4,6-trinitrotoluene (TNT), RDX and Octahydro-1,3,5,7-tetranitro-1,3,5,7-tetrazocine (HMX) in soil samples ${ }^{44}$; thermal energy analysers coupled with liquid chromatographic techniques have been found to be more sensitive than $\mathrm{ECD}^{45}$; and mass spectrometric techniques, as well as others, are capable of detecting explosives in the picogram levels ${ }^{46}$. Spectroscopic techniques such as surface enhanced Raman spectroscopy have also been extensively developed and with the availability of small portable instruments can be used for screening of potential explosive residues ${ }^{47}$ or even stand-off detection of postblast residues ${ }^{48}$. Despite the development of a multitude of instrumental techniques capable of detecting and quantifying trace levels of explosives (with recent advances collated in a review, cf. Klapec and Czarnopys, $2013^{49}$ ), access to these instruments is not always possible in all laboratories. A sound knowledge base in the distribution of post-blast residues would allow sample collection to be optimised based on the analytical equipment available, i.e. collection in areas known to provide a better chance of yielding quantities at or above the LOD of available instrumentation. Conversely, if distances beyond a radius from the detonation centre can be recognised as requiring more vigorous analytical techniques with lower LODs, samples could be prioritised for techniques of appropriate sensitivity.

2) The fireball: the inner zone consists of hot incandescent gases (the fireball); any undecomposed explosive which is projected but adheres to a close surface may subsequently be engulfed in the fireball and decomposed in this later stage. This is also reiterated elsewhere where it is stated that the exposure of the flame front can impinge on close surfaces, depending on their thermal inertia ${ }^{50}$. The fireball radius is given in the text $\mathrm{t}^{3}$ by equation 3 where $\mathrm{W}$ is the mass of the explosive charge:

$$
\mathrm{r}=\mathrm{W} / 3
$$

Equation 3 does not explain the relationship between charge mass and fireball radius effectively; as blast effects usually follow cube root scaling, the fireball radius could be scaled with the cube root of TNT equivalence of the charge mass to give $r \sim \mathrm{W}^{1 / 3}$.

3) The nature of the surface: no surfaces within the zone in which detectable residues and traces may be expected should be neglected, but some surfaces, like fabrics, are more likely to have residues than wood, which will have more residue than metal ${ }^{3}$. The amount of explosives recovered from different surfaces is therefore also governed by the efficiency of the appropriate sampling method used to remove the residues from that surface, i.e. swabbing from non- 
porous surfaces, vacuuming from fabric surfaces or direct solvent extractions. The detection capability of each of these varies depending on multiple criteria such as: the type of swab; the solvent type and amount (if one is used); clean-up procedure required; extraction methods; vacuum detector LOD; contaminant collection; etc. $^{51-53}$. Depending on combinations of these criteria, as well as the nature of the explosive analyte being detected (including whether it is thermally labile), the sampling efficiencies vary greatly ${ }^{51}$. Again, if no prior knowledge of the explosive material is available, sampling procedures must be able to collect residues from a wide range of potential explosives, which in turn can potentially raise the LOD, particularly in the case of choosing appropriate swabbing materials. This further highlights the importance of understanding where explosive residues are likely to have deposited in order to ensure sampling in, and from, optimum locations.

4) Orientation of the surface: generally only surfaces that are facing the direction of travel of the blast wave will have received the majority of deposited material ${ }^{3}$. Nonetheless, surfaces facing the opposing direction should not be ignored, particularly those close to the centre of the detonation where residues upon 'detonation facing' surfaces may have decomposed due to the fireball as mentioned previously, yet it may be possible that residues on the back of these surfaces may not have.

The four factors discussed from this particular text $\mathrm{t}^{3}$ denote important criteria to consider which will affect the finding of explosive residue. The inverse square law model suggested has also been further developed to include the trajectory path of the residues using ballistics equations ${ }^{18}$. This indicates more residue by mass may actually be found further away from the centre contrary to other suggestions that most undetonated residue will be found near the centre of the detonation ${ }^{5,54}$. By considering the subsequent movement of residues within a hemisphere above the point of detonation and assuming the particles are of equal mass and moving at equal speeds and projected at all angles above the horizontal, the angle of projection can be plotted against the range of the material ${ }^{18}$. If the trajectory of the explosive residue terminates at this theoretical hemisphere, the residue distributed within a particular segment is equivalent to that which falls on the section of ground covered between the two angles, i.e. the mass of material at longer range from the centre would be concentrated in a smaller area compared to closer to the centre (Fig. 2).

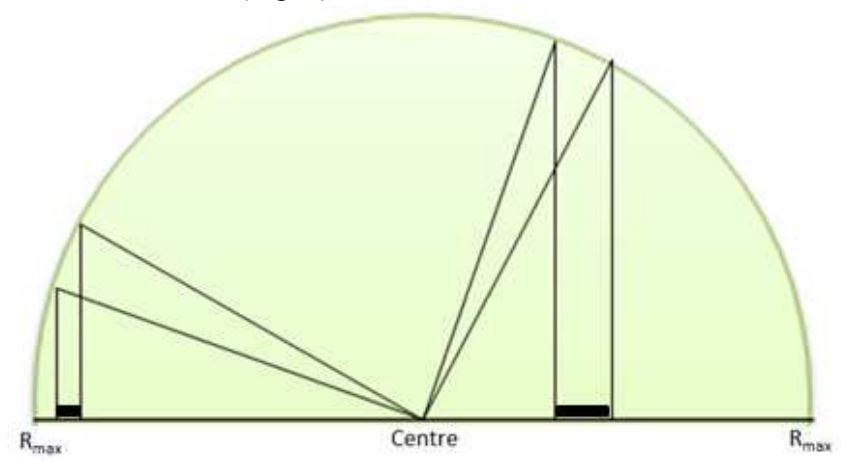

Figure 2: Distribution of residue based on dispersion angle: the same segments cover different sized areas on the ground, further away less area is covered and therefore more residues by mass are found further, compared to closer to the centre.

However, none of the models take into account the effects of the size of the explosive residues being dispersed, the residue trajectory angles (other than above the horizontal), or directionally biased movements due to the position of the detonator for example ${ }^{17}$. Furthermore, gravitational effects and environmental influences such as the wind velocity and direction ${ }^{17,54}$ which may affect the explosive residue distribution should be considered within the models. Nevertheless the models do provide a theoretical platform upon which the distribution of undetonated explosive residue can be built and there is some experimental work published which supports these distribution models.

\section{Explosive Residue Distribution - Experimental Research Studies}

One method of obtaining a clearer understanding of the distribution patterns of post-blast explosive residue would be the use of taggants. The incorporation of additives (including particulate, isotopic and biological ${ }^{55}$ ) to explosive materials to produce 'taggants' which can be used to identify explosives both pre and post-blast has been investigated extensively ${ }^{5-57}$. Identification taggants which can survive an explosion have been utilised in Switzerland to aid postblast investigations ${ }^{58,59}$, however whilst taggant use is technically feasible, it is not a wholly positively accepted idea (principally due to cost and safety concerns) and has therefore not been widely implemented $^{60,61}$. Taggants have however recently been used in research to assess the spatial distribution of post-blast explosive residues. Various lanthanide taggants were used as chemical indicators of explosive residue following the detonations of homemade explosive mixtures and were collected from uniformly positioned collection media positioned on the ground surrounding the explosive charge and subsequently analysed with inductively coupled plasma mass spectrometry (ICP-MS) ${ }^{62}$. Despite attempts at establishing the spatial distribution of the explosive residue, it is the distribution of the lanthanide taggant which is actually reportable and the correlation between the two remains unverified. This highlights an important point to consider when using taggant material for identifying spatial residue trends - the taggant must be incorporated as a part of, or bound to, the explosive molecule in order to conclude the distribution of the explosive itself rather than that of the taggant. No other studies which have examined the spatial distribution trends of post-blast residues using taggants were found at the time of writing. However, experimental work which has not utilised taggants but assessed the dispersal of explosive residue has been conducted.

A noteworthy set of experiments were done by the UK Forensic Explosives Laboratory (FEL) and US Federal Bureau of Investigation (FBI) assessing the physical and chemical evidence remaining after the explosion of large improvised bombs ${ }^{43,63,64}$. In the first trials, witness materials, including cars and metal signposts, were positioned at increasing distances about the detonation centre ${ }^{63}$ and the residue recovery from inorganic charges was determined. Whilst this paper discusses the sampling and analysis procedures 
employed by the FEL and the FBI, it also includes the residue concentrations recovered from the various sampling sites. Of the samples taken from car doors, the residue recovery rates increased with increasing distance of the vehicles from the charge (for example $84 \mu \mathrm{g}(4.6 \mathrm{~m}) \rightarrow 128 \mu \mathrm{g}(15.2 \mathrm{~m}) \rightarrow 156 \mu \mathrm{g}(22.9 \mathrm{~m})$. The recovery from signposts decreased with their increasing distance from the charge centre, the lowest concentrations were detected near 60 metres away and thus provide some support for the 60 metre theoretical radius ${ }^{18}$ in which residue could be found. From the second trials, the explosive residue concentrations generally decreased with increasing distance in any given direction from most sampling sites (for example $10750 \mu \mathrm{g}(15 \mathrm{~m}) \rightarrow 4678 \mu \mathrm{g}(23 \mathrm{~m}) \rightarrow$ $1616 \mu \mathrm{g}(30 \mathrm{~m}) \rightarrow 0 \mu \mathrm{g}(46 \mathrm{~m})$. However, quantities recovered at equal distance but different orientations about the centre were not comparable, indicating the influence of some directional factor ${ }^{64}$. For the final set of firings ${ }^{43}$ the residue recovery generally decreased with distance in all directions but various orientations were again not comparable. The authors explain that these variations indicate residue deposition occurs primarily due to the dust or smoke cloud and not the initial shock wave. These experimental findings contradict theories which discuss the effects of the positive and negative blast pressures on the pushing and impedance of particles $^{3,18}$ and those which consider dispersion angle to affect the distribution $^{18}$. Figures 3 and 4 show some of the nitrate and ammonium analyte recoveries following the detonations of inorganic charges from this series of papers and principally show the reduction in analyte recovery with increasing distance for one orientation about the centre; the nitrate detection being much higher overall potentially due to the oxidation of ammonium during the explosions $^{64}$, yet the general patterns were very similar between the two analytes.

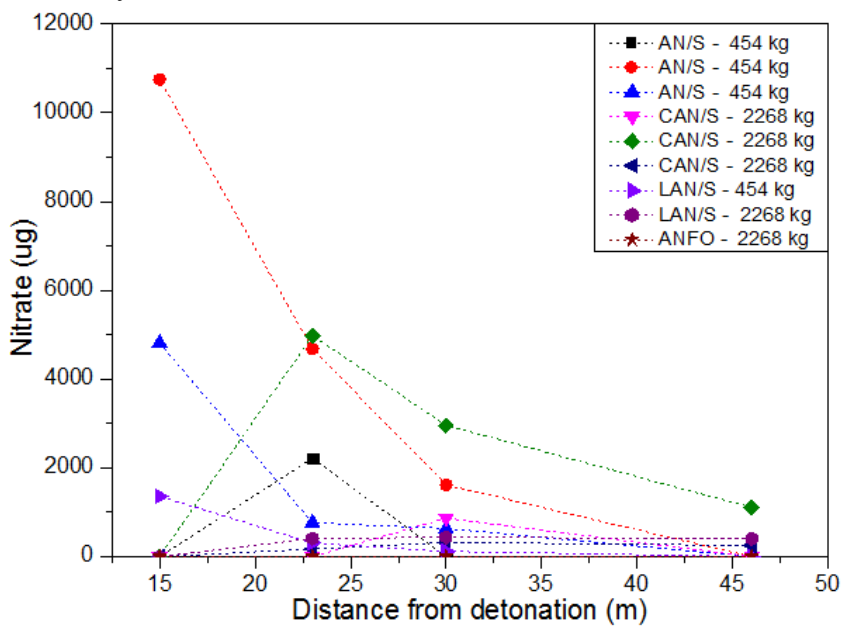

Figure 3: Recovery of nitrate ( $\mu \mathrm{g})$ from sites positioned at increasing distances from detonations of inorganic charges from Phillips et al ${ }^{63}$, Cullum et al $l^{64}$ and Monsfield et al ${ }^{43}$.

Organic charges were also detonated in the third set of trials ${ }^{43}$ from which significant residue concentrations were recovered from both the front and back of the road signs (the majority on the front), however the levels did not decrease with increasing distance, but rather increased in some directions, contrary to the inverse square law model of distribution, but consistent with theories which state less residue will be found nearer the centre ${ }^{18}$. Whilst variations between the residue distribution patterns between the inorganic and organic charges were clear, these were not discussed in detail in these papers. The results may indicate variability in distribution pattern of residue depending on the type of explosive, which would also counter some theoretical foundations which indicate distribution patterns are independent of explosive type ${ }^{18}$.

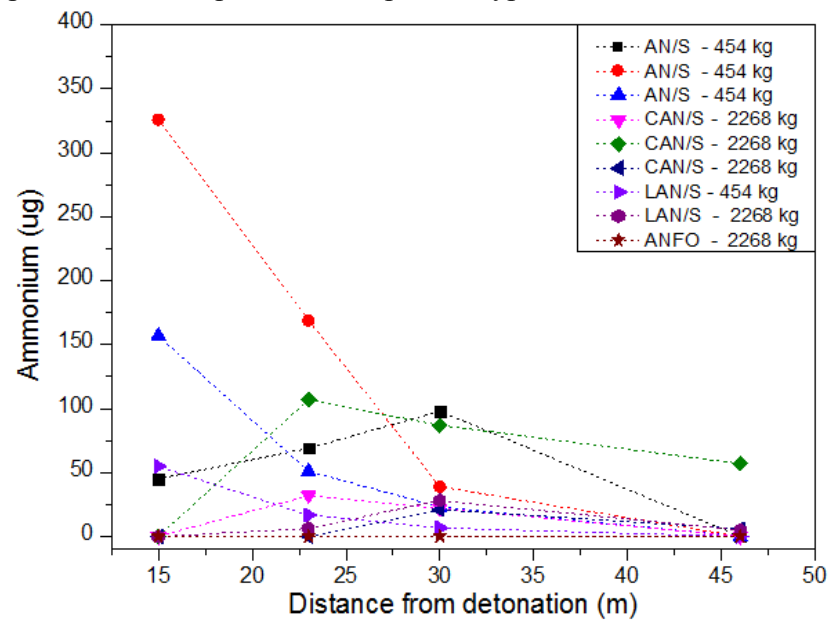

Figure 4: Recovery of ammonium ( $\mu$ g) from sites positioned at increasing distances from detonations of inorganic charges from Phillips et al ${ }^{63}$, Cullum et al ${ }^{64}$ and Monsfield et a $f^{43}$.

These studies are an important foundation for residue distribution research as they demonstrate generic distribution patterns of decreasing concentrations as a function of distance from the centre, and also provide a good basis for experimental work. Although the findings from these experiments are limited to very large inorganic charges and the applicability of the results to much smaller charges and further materials is unknown, they highlight important methodological requirements such as recording the blast wave pressures and potentially important variables to take into consideration such as the sampling height from the ground and the sampling site material itself.

Studies in which the focus was not primarily on explosive residue distribution have also provided experimental data. In an experiment designed to assess the application of analytical techniques to the detection of post-blast explosive residues from TNT and Dynamite charges, samples were collected from the detonation centre and at distances of 1 and 2 metres ${ }^{17}$. The authors found unreacted particles at all sites, however the distribution varied between the different charge masses and explosive types. In some cases the residue concentrations increased with increasing distance, in others they decreased. Higher concentrations were recovered 1 metre away compared to at the centre, but decreased at 2 metres (figure 5). The authors also noted that the unreacted explosive particles were irregularly dispersed on the 1 x 1 metre surfaces upon which they were collected in the vicinity of the explosion ${ }^{17}$. The distribution of residue was explained as being due to the acceleration of particles due to the expansion of gases with the final phase of movement determined by the wind. The authors suggest the particles become heated by the shock wave, and in some cases have the form of droplets, which subsequently solidify on cold surfaces of the surrounding environment ${ }^{17}$. This condensation of hot gases, soot and 
molten residue deposits which are exposed to cool adjacent surfaces has also been stated elsewhere ${ }^{65}$. Figure 5 displays the data gathered from this work and illustrates both the trend of decreasing residue concentrations with increasing distance as well as those of higher concentrations at the mid-sampled distance from different size TNT and dynamite charges. The recovered amounts of different analytes may be dependent on the chemical nature of the analyte itself or the sensitivity of the analytical technique as discussed previously. The authors analysed for TNT, DNT (2,4-dinitrotoluene), EGDN (ethylene glycol dinitrate) and NG (nitroglycerine) with gas chromatography coupled to an electron capture detector and reported limits of detection of $0.05 \mathrm{mg} / 1,0.1 \mathrm{mg} / 1,2.5 \mu \mathrm{g} / 1$ and $5 \mu \mathrm{g} / 1$ for each target analyte respectively. Figure 5 also indicates the amount of original explosive material may have an effect on the recovered concentrations, however with few repeated tests, this cannot be confirmed.

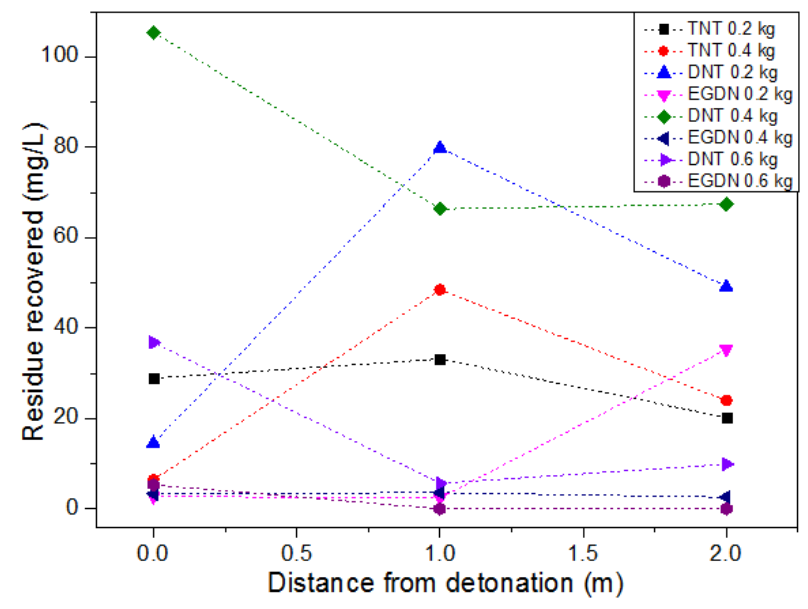

Figure 5: Recovery of dynamite explosive residues from detonation centres and 1 and $2 \mathrm{~m}$ from them, from Varga \& Ulbrich ${ }^{17}$.

Researchers investigating how to elucidate different dynamite brands from post-blast residues observed damage to plates positioned 1 metre away from the detonation centre, residue in the form of grey coatings on surfaces at 2.5 metres, visible residue particles at 5 metres from the centre, and few residue particles at 7.5 and 10 metres $^{54}$. The authors describe the finding of particles from a $500 \mathrm{~g}$ charge at $10 \mathrm{~m}$ from the centre and explain that particles would have been dispersed by the shockwave when it reached the boundary between the explosive charge and the air. Because of their higher mass compared to micro-droplets in the explosion gases, these particles would have higher kinetic energy and moved further from the detonation centre ${ }^{54}$. The authors also concluded that the 2.5 to 5 metre distances were optimal for obtaining valuable results for their work and was where the maximum concentrations were recovered (185.62 $\mu \mathrm{g}$ EGDN, 143.21 $\mu \mathrm{g}$ TNT, 50.03 $\mu \mathrm{g} \mathrm{NG}, 32.97 \mu \mathrm{g} \mathrm{DNT})^{54}$, however this finding is based only on particular charge masses and no distribution trend which factors in various charge sizes was apparent. Furthermore, whilst the research does comment on the distribution of the undetonated residues, the results may not actually be indicative of distribution as the charges in this study were initiated in a manner which biased the directional expansion of the gaseous products, and therefore influenced residue deposition.
A summary of the pertinent methodological aspects of the experimental work discussed so far is provided in table 1; the explosive charge types vary in composition and mass and the sampling sites (mainly non-porous) are overall positioned at various distances and orientations around the charge centre for most experiments. Similar techniques and results have come from studies which have focused on ground sampling for explosive residue. One study used metal sampling sites positioned on the ground around the detonation centre of $100 \mathrm{~g}$ spherical charges of RDX-based polymer bonded explosives ${ }^{66}$. The main trend found was the decrease in residue concentration with increasing distance from the centre, whilst slightly skewed with the wind direction.

More significant contribution to ground sampling and explosive residue distribution literature is also available from an environmental perspective. The fate and distribution of energetic material residues on military training grounds has been studied extensively in order to better maintain and ensure thorough management of training ranges and to control the leaching of explosive residues into groundwater. Studies have been based on sampling in and around areas of known detonations on firing ranges as well as the detonation of military explosives, including various sized mortar rounds and shells, and have focused on ground sampling; incorporating techniques such as multi-increment sampling ${ }^{67-69}$, sampling on tarpaulin ${ }^{70,71}$, snow $^{72-74}$, soil $^{67,69}$, and trays ${ }^{75}$. Studies which have used incremental sampling of soil have found a drop in residue recovery around firing points with increasing distance from the charge ${ }^{67}(4,200 \mathrm{mg} / \mathrm{kg}$ of NG in soil at the firing point $\rightarrow 142 \mathrm{mg} / \mathrm{kg}$ of NG at the furthest sampled distance). Another found residues of TNT $(0.02-7.5 \mathrm{mg} / \mathrm{kg})$ in soils sampled near the firing points with no residue detected elsewhere ${ }^{68}$. Similarly, low concentrations of RDX $(0.004 \mu \mathrm{g} / \mathrm{g})$ were found $5 \mathrm{~m}$ from the known firing point in one study with no residues detected at points sampled up to $50 \mathrm{~m}^{\text {away }}{ }^{69}$. Samples from these studies were not collected immediately after detonations but rather from areas known to have had detonations occur in the past. The results are therefore subject to degradation of residues over time and also cannot be assigned to one particular detonation event due to multiple firings occurring on such military ranges.

In order to circumvent the issue of knowing whether or not collected residues were from a particular detonation or not, one study used snow as a sampling medium and focused sample collection on the darker soot regions left on the snow around the detonation centre, possible introducing density bias into the collection strategy ${ }^{74}$. Furthermore, the authors only reported the concentrations of RDX $(0.025-8.5 \mathrm{mg})$ and TNT $(0.0052-1.1 \mathrm{mg})$ recovered from these firings and did not comment on distribution patterns. Another study investigated the quantities of residues recovered from the detonations of landmines on snow surfaces and found the highest concentrations of TNT residue 4 metres from the detonation point $\left(199 \mu \mathrm{g} / \mathrm{m}^{2}\right)$, second highest concentrations at 10 metres $(25.2$ $\mu \mathrm{g} / \mathrm{m}^{2}$ ) and a drop to $0.1 \mu \mathrm{g} / \mathrm{m}^{2}$ TNT at the furthest sampled point $\sim 24$ metres $^{73}$. RDX recoveries were greatest at the firing point (11.9 $\left.\mu \mathrm{g} / \mathrm{m}^{2}\right)$ with little RDX residue $\left(0.13-1.8 \mu \mathrm{g} / \mathrm{m}^{2}\right)$ recovered elsewhere $^{74}$. 
Table 1: Methodological aspects of forensic experimental work

\begin{tabular}{|c|c|c|c|c|c|c|c|}
\hline Ref. & $\begin{array}{l}\text { Explosive } \\
\text { Charge }\end{array}$ & $\begin{array}{c}\text { Charge } \\
\text { mass (kg) }\end{array}$ & $\begin{array}{l}\text { No. of } \\
\text { firings }\end{array}$ & Target analytes & $\begin{array}{c}\text { Sampling/witness } \\
\text { material }\end{array}$ & $\begin{array}{c}\text { Distance from } \\
\text { charge centre (m) }\end{array}$ & $\begin{array}{c}\text { Position/ } \\
\text { Orientations } \\
\end{array}$ \\
\hline 63 & $\mathrm{AN} / \mathrm{S}$ & 455 & 3 & $\mathrm{NH}_{4}+, \mathrm{NO}_{3-}^{-}$ & $\begin{array}{l}\text { metal road signs } 3.1 \mathrm{~m} \\
\text { from ground } / \text { cars }\end{array}$ & $\begin{array}{c}7.6,15.2,22.9 \\
30.5 / 2.1,4.6,15.2 \\
22.9\end{array}$ & $\mathrm{~N}, \mathrm{E}, \mathrm{S}, \mathrm{W}$ \\
\hline 63 & Urea nitrate* & 545 & 1 & $\mathrm{n} / \mathrm{a}$ & $\mathrm{n} / \mathrm{a}$ & $\mathrm{n} / \mathrm{a}$ & $\mathrm{n} / \mathrm{a}$ \\
\hline 64 & $\mathrm{CAN} / \mathrm{S}$ & 454 & 3 & $\mathrm{NH}_{4}+, \mathrm{NO}_{3^{-}}$, glucose & metal road signs/cars & $\begin{array}{c}8,15,23,30,60 / 5 \\
15,23,30\end{array}$ & $\mathrm{~N}, \mathrm{E}, \mathrm{S}, \mathrm{W}$ \\
\hline 64 & $\mathrm{CAN} / \mathrm{S}$ & 2268 & 3 & $\mathrm{NH}_{4}+, \mathrm{NO}_{3^{-}}$, glucose & metal road signs/cars & $\begin{array}{c}15,23,30,46 \\
60 / 15,23,30,46\end{array}$ & $\mathrm{~N}, \mathrm{E}, \mathrm{S}, \mathrm{W}$ \\
\hline 43 & $\mathrm{LAN} / \mathrm{S}$ & 454 & 3 & $\begin{array}{l}\mathrm{NH}_{4}+, \mathrm{NO}_{3^{-}}, \mathrm{Ca}, \mathrm{Mg}, \\
\text { glucose, fructose }\end{array}$ & $\begin{array}{c}\text { metal road } \\
\text { signs/cars/soil }\end{array}$ & $\begin{array}{c}8,15,23,30,60 / 5 \\
15,23,30\end{array}$ & $\mathrm{~N}, \mathrm{E}, \mathrm{S}, \mathrm{W}$ \\
\hline 43 & $\mathrm{LAN} / \mathrm{S}$ & 2268 & 3 & $\begin{array}{l}\mathrm{NH}_{4}+, \mathrm{NO}_{3^{-}}, \mathrm{Ca}, \mathrm{Mg}, \\
\text { glucose, fructose }\end{array}$ & $\begin{array}{c}\text { metal road } \\
\text { signs/cars/soil }\end{array}$ & $\begin{array}{c}15,23,30,46 \\
60 / 15,23,30,46\end{array}$ & $\mathrm{~N}, \mathrm{E}, \mathrm{S}, \mathrm{W}$ \\
\hline 43 & TNT & 454 & 1 & TNT, RDX & $\begin{array}{c}\text { metal road } \\
\text { signs/cars/soil }\end{array}$ & $\begin{array}{c}8,15,23,30,60 / 5 \\
15,23,30\end{array}$ & $\mathrm{~N}, \mathrm{E}, \mathrm{S}, \mathrm{W}$ \\
\hline 43 & ANFO & 2268 & 1 & $\mathrm{NH}_{4}+, \mathrm{NO}_{3}^{-}$ & metal road signs/cars & $\begin{array}{c}15,23,30,46 \\
60 / 15,23,30,46\end{array}$ & $\mathrm{~N}, \mathrm{E}, \mathrm{S}, \mathrm{W}$ \\
\hline $17 * *$ & TNT & $0.2 / 0.4$ & 2 & TNT & $\begin{array}{l}\text { stone surfaces, } 1 \mathrm{~m}^{2} \\
\text { metal plates }\end{array}$ & $0,1,2$ & 1 orientation \\
\hline $17 * *$ & $\begin{array}{l}\text { Dynamite - } \\
\text { Danubit } 2\end{array}$ & $0.2 / 0.4 / 0.6$ & 3 & $\begin{array}{c}\mathrm{DNT}, \mathrm{EGDN}, \mathrm{NH}_{4}+ \\
\mathrm{NO}_{3^{-}}, \mathrm{Na}+\end{array}$ & $\begin{array}{l}\text { stone surfaces, } 1 \mathrm{~m}^{2} \\
\text { metal plates }\end{array}$ & $0,1,2$ & 1 orientation \\
\hline $54^{* *}$ & $\begin{array}{l}\text { Dynamites: } 6 \\
\text { brands }\end{array}$ & $\begin{array}{l}0.5 \text { quoted } \\
\text { once, } \\
\text { others }\end{array}$ & $\begin{array}{l}1 \text { of } \\
\text { each }\end{array}$ & EGDN, DNT, TNT, NG & $1 \mathrm{~m}^{2}$ steel plates & $1,2.5,5,7.5,10$ & 1 orientation \\
\hline
\end{tabular}

* Not sampled for; ** Not primarily testing for dispersal of residues

Inorganic charges $=$ Ammonium nitrate based; Organic charges $=2,4,6$, Trinitrotoluene $(\mathrm{TNT})$, Dynamites

$\mathrm{S}=$ sugar; $\mathrm{AN}=$ ammonium nitrate $\mathrm{CAN}=$ calcium ammonium nitrate; $\mathrm{LAN}=$ limestone ammonium nitrate; $\mathrm{ANFO}=$ ammonium nitrate fuel oil.

Danubit 2 composed of: ethylene glycol dinitrate (EGDN), nitroglycerine (NG), nitrocellulose (NC), dinitrotoluene (DNT), AN, sodium nitrate (SN), wood

flour, carboxymethylcellulose, micro-ground limestone and ferric oxide (as a dyestuff) ${ }^{17}$.

A further study which collected from snow following high order detonations also found the highest residue concentrations (TNT) were recovered from the sampling points closest to the detonation centre: $1300 \mathrm{mg} / \mathrm{m}^{2}(1.5 \mathrm{~m}) \rightarrow 340 \mathrm{mg} / \mathrm{m}^{2}(4 \mathrm{~m}) \rightarrow 140 \mathrm{mg} / \mathrm{m}^{2}(6.6$. $\mathrm{m})$. The same decreasing concentration trend was also seen from different orientations around the centre, however the recovered concentrations were not comparable: for example; $330 \mathrm{mg} / \mathrm{m}^{2}$ at 1.8 $\mathrm{m} \rightarrow 19 \mathrm{mg} / \mathrm{m}^{2}$ at $2 \mathrm{~m} \rightarrow 1 \mathrm{mg} / \mathrm{m}^{2}$ at $4.4 \mathrm{~m}$; indicating a bias in direction as also seen from the forensic studies outlined previously.

Assessment of low order (or partial) detonations have found that they produce heterogeneous residue distributions ${ }^{70}$ of particles (of which the majority of masses were $>12.5 \mathrm{~mm}$ in diameter), with no consistent relationship found between residue mass deposition on the ground (on tarpaulin) and distance from the centre. The studies which have assessed the residue distributions from low order firings did so by sweeping predetermined radii around the detonation centre and reporting residue amounts as a collective amount within particular distances - hence, no orientation bias is reported. The total mass of residue recovered in one study, measured at 3, 6, 9, 12 and $15 \mathrm{~m}$ from the charge detonation varied between 0 and $300 \mathrm{~g}$ with less than $150 \mathrm{~g}$ recovered at the furthest sampled distance ${ }^{70}$. Other research has also found low order detonations randomly scattered large chunks of residue, and any smaller particles decreased in mass with increasing distance from the centre ${ }^{76}$. Based on results from the partial firing of rounds ranging between $60-155 \mathrm{~mm}$ in diameter, an $18 \mathrm{~m}$ radius within which residues would be distributed from low order detonations was concluded ${ }^{70}$. In contrast, a limiting radius of 15 metres within which residues from high order detonations of artillery munitions rounds (ranging from $60-155 \mathrm{~mm}$ in diameter) was found where the total mass of explosive residue recovered per firing was $<100 \mathrm{mg}^{71}$. This implies low order detonations distribute residues at greater distances than high order detonations. The kinetic energy of the larger mass deposits produced from low order detonations would cause them to be deposited further away compared to the smaller particles from high order or near-complete detonations where the mass of residue recovered from sampling sites decreased with increasing distance from the centre of the detonation $^{70}$. When comparing different charge sizes, smaller munitions were found to deposit less residues which were recovered closer to the detonation centre, compared to larger munitions ${ }^{76}$; this counters theories that the larger the charge the less likely it will be to find undetonated material ${ }^{3}$. Some of the larger explosive charges from the forensic studies ${ }^{43,63,64}$ also produced higher mass depositions, but this was not always the case.

The ground distribution patterns from these environmental studies offer valuable insight to undetonated explosive residue distribution patterns. As the primary goal of the research was to assess contamination of training grounds, the results do not include information which would be pertinent to a forensic scenario such as perpendicular site sampling, which has been noted as more lucrative 
for forensic sampling of explosive residues ${ }^{77}$. However they do provide insight to additional important variables such as the charge size, which is currently neglected in theoretical models for residue distribution. The environmental studies reviewed here form a set of experiments conducted by the US Army Corps of Engineers, Engineer Research and Development Centre (ERDC). Whilst data has been referred to here, for full methods and collated results from all the environmental ground sampling research conducted during this ERDC project, please cf. Pennington $(2006)^{78}$ for the final report published by the group.

Experimental investigations in explosive residue distribution are limited to the forensic and ground sampling environmental works discussed. Between the studies a small range of explosive charges and masses have been tested, however given the variations in residue recovery of different target analytes, repeated experiments with further explosives, of further masses in varying confinements, should be tested to determine conclusive distribution trends. The amount of explosive residue in each case has also been dependent on the analytical technique used as mentioned previously; the resulting values reported in each study are therefore not reliably comparable across datasets from different experiments. Standardised techniques for detecting trace explosive residues, such as the US Environmental Protection Agency (EPA) method for detecting $\mathrm{RDX}^{79}$, should be used where possible. Additionally, the positioning of the sample sites should not be restricted to compass points but should aim to cover as much area around the charge centre as possible (ideally both perpendicular to, and on the ground) in order to produce a comprehensive dataset of explosive residue distribution. Furthermore, whilst general trends are apparent in the results, obvious directional biases due to potential environmental conditions are also clear. Further experiments which incorporate a thorough measurement of meteorological conditions are necessary.

It is vital that an empirical evidence base for the formation and dispersal of undetonated residues be established, therefore experimental studies are fundamental. The expense of the investigations and trial requirements such as access to firing ranges, explosive material and personnel authorised to handle and detonate the charges are understandably difficult necessities to overcome. Furthermore, the need to replicate experiments in order to produce verifiable findings and therefore generate significant conclusions is hampered by these constraints. Computer aided simulation techniques have been applied to model various explosion phenomena and offer a useful tool for investigating multiple scenarios and allow for numerous repeat measurements to be obtained.

\section{Residue Distribution Simulation Models}

Detonation and shock modelling capabilities have been developed over decades to produce models that can improve knowledge and understanding of the processes occurring during detonation, in both chemical and physical terms, as well as to assess the damage that can impact a structure in order to build safer, strengthened buildings. The models for both gaseous and condensed phase explosives are based on complex equations; from a thermodynamic perspective the condensed phase detonations can be modelled with thermochemical calculations, non-ideal detonation and divergent flows, and hydrocodes (which allow flowing systems to be modelled by using three dimensional cell matrices) or full numeric simulations ${ }^{80}$. Models for various detonation modelling purposes, evolved for example from research into effects of blast on buildings ${ }^{81}$, have predominantly focused on calculating peak pressures from the leading shock wave.

Despite the wealth of detonation modelling literature, relatively little research has been carried out in the arena of condensed phase residue particle distribution. The distribution of solid particles from the point of detonation to post-blast movement either in the smoke plume or wind field is a complex problem to solve computationally, requiring extensive computing power, an understanding of the quantity of material which could become airborne ${ }^{82}$, and expressions which consider factors such as the explosive strength and total mass of other materials present ${ }^{83}$. The modelling process needs to be broken down into stages which reflect the various aspects of detonation $^{84}$.

The choice of modelling methodology depends closely on which regime of the detonation process that is of interest. It is generally too computational demanding to model the entire range of chemical and physical processes involved in one large simulation; ranging from the generation of detonation products inside the explosive to the deposition of residue particles in a complex urban environment. The simulation is therefore usually divided into separate parts each representing a specific physical process. The rationale for this strategy is that the processes involved in detonation occur at very different time scales, ranging from milliseconds to seconds or minutes, and that the physically characteristics of each stages therefore are amendable to simplifying modelling assumptions necessary to reduce the overall computational cost. From a physical modelling prospective the following regimes are practical: (i) detonation wave modelling inside the explosive, (ii) blast wave modelling outside the explosive, and (iii) atmospheric transport and deposition modelling.

From a forensic or environmental application point-of-view, on the other hand, it is more suitable to jointly consider regimes (i) and (ii) as Source modelling whereas regime (iii) is retained as Atmospheric transport and deposition modelling. These two modelling stages can sometimes be decoupled due to extreme separation of time scales; the time scales associated with the explosive source is in the order of milliseconds, whereas the corresponding time scale for the atmospheric transport and deposition is in the order of seconds or minutes. Arguably, particle deposition on surfaces in the immediate vicinity of the charge occurs on the same time scale as the explosion itself but the terminology 'atmospheric transport' used here alludes to spatial scales ranging from a few meters up to 10 s and 100 s of meters from the source. There also exists an intermediate time-scale range at which a decoupling of the problem not is valid. That is if the effect of the velocity, pressure, and thermal fields induced by the detonation is of the same order as the effect of ambient atmospheric conditions on the residue particle transport and deposition. This time scale is typically in the order of a few seconds for an outdoor 
detonation under typical atmospheric conditions and it is usually the strength of the buoyant plume that defines the upper limit. This time scale can thus increase significantly under very calm ambient conditions or if the detonation occurs indoor.

Relevant work in modelling particle distribution following a detonation includes research into the dispersal of radiological material from 'dirty' bombs ${ }^{85}$, modelling the velocity of explosive products $^{86}$ and estimations of dispersal based on the smoke cloud volume and height, however they do not directly or fully address the distribution of undetonated explosive residues upon and following detonation. Atmospheric dispersion models initially developed to predict the downwind concentration of air pollutants emitted from sources such as industrial plants are now being applied to explosive releases. In this review the primarily focus of our attention is on state-of-the-art atmospheric transport and deposition models relevant for forensic and environmental science applications associated with explosive releases in complex urban environments.

\section{Source modelling}

The source model represents the combined effect of the initial detonation wave that converts the explosive material to detonation product (regime i), and the subsequent gas-dynamical processes taking place in the immediate vicinity of the explosive (regime ii). The primary output from the source model consists in general of the three-dimensional velocity, pressure, and temperature fields, and the velocity, temperature, and spatial distribution of residue particles. These fields are subsequently used as initial conditions for the atmospheric transport and deposition model described in the next subsection.

When an explosive charge is detonated, a detonation wave propagates through the explosive material as explained previously. The detonation wave is a reactive shock wave that converts the explosive material into detonation products. The exact characteristics of the detonation wave depend inherently on the chemical composition of the explosive and detailed computational modelling of these processes is therefore very demanding. It is however oftentimes sufficient to adopt a simplified approach which rests on the assumption that the charge is consumed by one dimensional, constant-velocity Chapman-Jouguet detonation wave ${ }^{87-89}$. This shock separates the unburned explosive material (in front of the shock) and burned products (behind the shock). Combined with an equation of state (EOS), the one dimensional Chapman-Jouguet relationships provide estimates of the density, pressure, and velocity of the gaseous detonation products and the speed of the detonation front. These fields are used as initial conditions for the subsequent shock wave simulations.

When the detonation wave reaches the edge of the charge, a blast wave propagates outwards through the air and a rarefaction wave propagates inwards through the gaseous detonation products. The interface between the detonation products and the air is swept outwards by the shock induced velocity field. This interface is characterized by relatively large density gradients, making it unstable to so-called Rayleigh-Taylor (R-T) and Richtmyer-
Meshkov (R-M) type instabilities ${ }^{90}$. These instabilities can further develop into a turbulent mixing layer that efficiently mixes air and detonation products which enhances the effect of afterburning. Compared to the time scale of the initial detonation wave, the combustion processes usually occurs at a finite rate. In cases where the combustion processes are modelled explicitly it is common to consider infinite reaction rates although advanced methods to account for finite rate chemistry exist ${ }^{91}$.

When bomb residue particles are present, effects of shock-particle interaction can be significant. The interaction of the gas and the particles may depend significantly on the inertia of the particles as well as their thermal properties. For heavy particles the induced inertia may become larger than the surrounding mixture of detonation products and air whereby the very high particle velocities may be retained for a long period of time. In extreme cases, the particle may even overtake the initial shock wave. Depending on the thermal properties of the particles, it may react, melt, or evaporate, and thus affect the overall energy balance. For a more thorough discussion cf. Balakrishnan (2010) ${ }^{92}$.

The size distribution and initial position of unburned residue explosive material is a priori unknown and it is very difficult, if at all possible, to simulate the detonation process sufficiently detailed or designing an experiment setup, to generate accurate predictions. Some experiments have been conducted based on a packed bed of inert solid particles moulded around a spherical explosive charge and it is the velocities of these which are reported rather than the unreacted particles of the explosive material itself ${ }^{93,94}$. Detailed information on unreacted particles is therefore sparse. Provided a one-way coupling between the gas and the particles can be assumed, i.e. that the gas affects the motion of the particles and not vice versa, the impact of this uncertainty can be significantly reduced in the simulation. This is simply achieved by systematically varying the particle size distribution and the initial positions of the particles within the initial residue cloud.

The explosive source is thus characterized by very complex physical and chemical multi-species and multi-phase processes occurring at extremely small time and spatial scales. These processes can in principle be accounted for by very advanced and computationally expensive simulation models based on the unsteady, compressible, reacting, multi-species Navier-Stokes equations. A detailed description of source model methodologies is however outside the scope of this review. The reader is encouraged to cf. e.g. Gottiparthi $(2014)^{95}$ and Kuhl (2013) ${ }^{96}$, for more details.

In summary, the source model provides estimated particle positions, velocity, temperature, size, and mass for use as initial conditions for the atmospheric transport and deposition model. Due to the scale separation between the source (a few meters) and the surrounding urban environment (100s of meters) it is generally advisable to generate the output of the source model at a point in time at which the impact of the detonation on the wind field can be neglected as compared to the ambient atmospheric conditions.

\section{Atmospheric transport and dispersion modelling}


There exist a plethora of atmospheric transport models, ranging from simple empirical models to models that essentially are based on the fundamental laws of conservation of mass, momentum, and energy. The latter category solves a number of coupled, non-linear partial differential equations that require large computing resources. Atmospheric transport models are traditionally grouped according to the required simulation time which varies depending on the field of application, cf. eg. Balczo et al (2012) ${ }^{97}$. At the one end, emergency response tools require very fast running models (order of minutes) whereas, on the other end, models suitable for emergency planning, exercises, and forensic analyses may require days and weeks of simulation time. It generally follows that as the demand for accuracy and reliability increases, the model complexity and associated computational cost also increases. This is particularly relevant for forensic studies that inherently require a high level of reliability.

The region of primary interest for both forensic and environmental applications associated with detonations in a complex urban environment is usually limited to hundred meters or so, sometimes even less. This has an important model implication since the aerial transport and surface deposition of particles generated by the detonation may depend strongly on building structures, topography variations, and vegetation; i.e. geometrical structures an order of magnitude smaller than the region of interest, e.g. tens of meters or less in this case. This also implies that, aside from the atmospheric conditions, local effects such as solar heating of walls and sidewalks, and traffic may need to be accounted for. Generally speaking, the geometrical details and the complexity of the physical processes thus increase as the area of interest decreases.

From a modelling point of view, however, the complexity of atmospheric transport is reduced as compared to the detonation processes (i.e. the source) described above. The most notable difference is that the incompressible fluid flow assumption usually can be invoked which implies a considerable smaller temporal and spatial scale separation. In addition, at a distance from the source, the residue particles can be characterized as dilute and solid which implies that there is no appreciable effect of the particles on the wind field, and that particle break-up and evaporation processes can be neglected.

The most generally applicable atmospheric transport modelling approach currently in use is incompressible Large Eddy Simulations (LES) combined with a Lagrangian tracking technique to model particle transport. The incompressible LES model is based on the numerical solution of the fundamental equations governing conservation of mass, momentum, and temperature, and it is currently the state-of-the-art simulation methodology used for reallife turbulence applications. Turbulent fluid motion is characterized by a continues range of temporal and spatial scales which in atmospheric flows typically vary from minutes to seconds, and from kilometers to centimeters, respectively. In LES the evolution of the three-dimensional large energy containing scales are directly simulated whereas the smallest spatial scales are approximated using a so-called subgrid stress (SGS) model; the computed LES velocity, pressure, and temperature fields are accordingly termed filtered fields.

The LES approach comprises of the numerical solution to the timevarying, three-dimensional Navier-Stokes equations governing the filtered velocity $\mathbf{u}(\mathrm{x}, \mathrm{t})$, pressure $\mathbf{p}(\mathrm{x}, \mathrm{t})$, and temperature $\boldsymbol{\theta}(\mathrm{x}, \mathrm{t})$ fields, respectively. The equations governing conservation of mass, momentum, and energy can for an incompressible fluid be written as, using Cartesian index notation:

$$
\begin{aligned}
& \frac{\partial u_{i}}{\partial x_{1}}=0 \\
& \frac{D u_{1}}{D t}=-\frac{1}{\rho t} \frac{\partial p}{\partial x_{1}}+\theta V^{2} u_{i}-\frac{\partial x_{1}}{\partial x_{I}}-\alpha g_{i}\left(\theta_{0}-\theta\right) \\
& \frac{\partial t}{D t}=\kappa v^{2} \theta .
\end{aligned}
$$

Here, $x_{i}$ and $t$ denote the Cartesian coordinate in the $i$-th direction and time, respectively, whereas $\rho, v$, and $\kappa$ are the fluid density, kinematic viscosity, and thermal diffusivity, respectively. The Boussinesq approximation is invoked in (2) (last term on the right hand side) in order to account for thermal effects on the velocity field ${ }^{98} ; \alpha$ is the thermal expansion coefficient and $g_{i}$ and $\Theta_{0}$ denote the gravitational vector in direction $\mathrm{x}_{\mathrm{i}}$ and a reference temperature, respectively. The third term on the right hand side in (2), $\tau_{\mathrm{ij}}$, represents the subgrid stress (SGS) model. There exist a relatively large number of SGS models but it is outside the scope of the present review to go into details about these, please cf. e.g, Pope $(2000)^{99}$ and Sagaut (2006) ${ }^{100}$ for more details.

Equations (1) - (3) are discretized and numerically solved at each time step on each grid point of a three-dimensional computational mesh subjected to appropriate boundary conditions. The computational mesh must be sufficiently dense in order to resolve the geometry of interest as well as the dynamical turbulence motion. The time step needs also to be small to resolve the temporal scales of the wind field. Evidently this becomes a very time consuming and computationally expensive process. Typically $10-100$ million grid points are required for a $500 \times 500 \mathrm{~m}^{2}$ urban area (with a smallest resolution in the order of decimeters) and the required temporal resolution typically in the order of $1 / 10 \mathrm{~s}$. Different computational algorithms exist with varying degree of accuracy and complexity that can be adopted to numerically solve the LES equations. This aspect of atmospheric transport modelling is however outside the scope of the present review, cf. e.g. Sagaut $(2006)^{100}$ for an overview.

Under the assumption of a dilute residue particle cloud the wind field and the particles can be considered as decoupled. This implies that the particles transport can be modelled separately given the computed time-varying and three-dimensional wind field as input. The most common approach is the Lagrangian particle transport model in which each particle, or parcels of particles, are tracked individual through the computational domain. Mathematically the particle transport model reads 


$$
\begin{aligned}
& \frac{d x_{b}}{d t}=u_{p} \\
& \frac{d u_{y}}{d t}=D\left(u-u_{p}\right)
\end{aligned}
$$

where $\boldsymbol{x}_{\mathrm{p}}, \boldsymbol{u}_{\mathrm{p}}$, and $\boldsymbol{u}$ are vectors associated with the particle position, particle velocity, and background velocity, respectively. The parameter $D$ represents the drag on the particle. A simple and commonly used drag law valid for spherical particles is

$$
D=\frac{18 \mu}{p_{p} d}\left(1+a R g_{p}^{b}\right)
$$

where $\boldsymbol{\mu}, \boldsymbol{\rho}_{\boldsymbol{p}}$, and $\boldsymbol{d}_{\boldsymbol{p}}$ denote the molecular viscosity of air, particle density, and particle diameter, respectively, whereas $a$ and $b$ are model constants. The coefficient $R e_{p}$ is the particle Reynolds number usually taken as

$$
R e_{p}=\frac{\left|u-u_{p}\right| d_{Y}}{b}
$$

For a general drag law for spherical particles cf. Maxey and Riley $(1983)^{101}$. The particle shape may sometimes also be influential and there exist more elaborate drag laws taken into account nonspherical particle shapes ${ }^{102}$. It should however be noted that the largest model uncertainties are usually associated with the background velocity field.

Equations (4) - (7) are solved for each particle given an initial particle position and velocity (at $t=0$ ), and the modelled background velocity field. It should be recalled that the background velocity field, $\boldsymbol{u}(\boldsymbol{x}, t)$, varies in time and space according the solution of the LES model; the background velocity field represents the turbulent advection of the particle and random perturbation of the particle position is thus not needed. If simpler approaches are used to model the atmospheric background field, e.g. the ReynoldsAveraged Navier-Stokes (RANS) approach (cf. e.g. Durbin and Pettersson Reif, $2010^{103}$ and Pope $2000^{99}$ ), then random perturbation of the particle trajectory is often necessary.

Particle deposition is a complex physical process that depends on a number of different factors including turbulence, particle properties, and surface characteristics, cf. e.g. Guha $(2008)^{104}$. In most practical situations the atmospheric background field can be assumed to be turbulent and in these cases the deposition rate is dominated by turbulent advection. If the atmospheric model is able to capture the large scale structures of the turbulent atmospheric boundary layer background, as is the case of the eddy-resolving method (LES) described above, particle deposition can simply be modelled using the Lagrangian approach by imposing the following rule: if the updated position of the particle at time step $n+1$, given the current particle velocity $\boldsymbol{u}_{\mathrm{p}}$ at time step $n$, is outside the boundary of the computational domain defined as a solid surface, the particle is considered as deposited on that surface. If simplified atmospheric models are used, e.g. RANS, other methods should be considered, cf. e.g. Hussein et al (2012) ${ }^{105}$.
In summary, the LES approach described here is the most generally applicable atmospheric transport model that is currently in use. Due its accuracy it is the most promising tool for forensic and environmental applications. The most notable challenge is the high computational cost which may imply weeks or even months of simulation time. Research is currently being undertaken to find ways to reduce the computational effort while retaining some of the accuracy. CT-Anlyst ${ }^{\circledR}$ is one such example which is developed by the Naval Research Laboratory (US), cf. e.g. Boris et al $(2010)^{106}$. Other simplified approaches include for instance QUIC-PLUME developed at Lawrence Livermore National Laboratories ${ }^{107}$. It is however outside the scope of the present review to provide a general extensive summary of all available models. Comprehensive overviews are given in e.g. Settles $(2006)^{108}$, Balczo et al $(2012)^{97}$, and Borysiewicz \& Borysiewicz (2006) ${ }^{109}$.

\section{Simulations example}

Recently, a simulation model based on the LES approach combined with Lagrangian particle tracking have been applied to model explosive residue particle releases, in particular of the residue depositions following the Oslo bombing in $2011^{77}$. This particular model has previously been applied and verified using wind tunnel data, to model the dispersal of bio-aerosols emitted form a biological treatment plant ${ }^{110}$ located in Norway. The objective of that study was to identify the possible source for the largest outbreak of Legionella that have occurred in Norway that caused several deaths.

The simulations of the Oslo bombing event in 2011 include the particle cloud following the detonation focusing on the wind as the dominant transport mechanism and were based on spherical particle sizes smaller than $20 \mu \mathrm{m}$, with a high density $\left(1000 \mathrm{~kg} / \mathrm{m}^{3}\right)$ and no particle-particle interactions ${ }^{77}$, i.e, dilute conditions were assumed. The extent and shape of the initial particle cloud, consisting of dust, debris, and possible bomb residue particles, was estimated using live footage obtained from surveillance cameras in the area, see Figure 6a. The shape and size of the cloud was estimated at the point in time were the atmospheric background dominated over the buoyant plume from the detonation.

Figure $6 \mathrm{~b}$ shows the modelled particle cloud 55 seconds after the initial release and figure $6 \mathrm{c}$ depicts the resulting deposition pattern of particles on building structures. Simulation results indicated perpendicular areas where the cloud had passed over to have the most residue depositions (15\%), with only $5 \%$ of the total residue particles emitted being deposited on the ground ${ }^{77}$. This trend is consistent with the experimental finding of lower concentrations of residue on the ground from some of the environmental and military studies. The authors concluded that the deposition of particles depended more on the source location (for example high on a roof, or low on the ground) and that dispersal was based more on the wind direction and velocity ${ }^{111}$.

This work constitutes the only known research which directly models the dispersal of explosive particles and attempts to establish their distribution patterns. In order to strengthen these efforts, work is currently underway to validate the models by comparison with 
experimental results. By doing so it will be possible to develop an accurate model which can be applied to assess explosion scenes and aid in the collection of trace residues as well as environmental cleanup procedures on military training grounds and industrial sites.

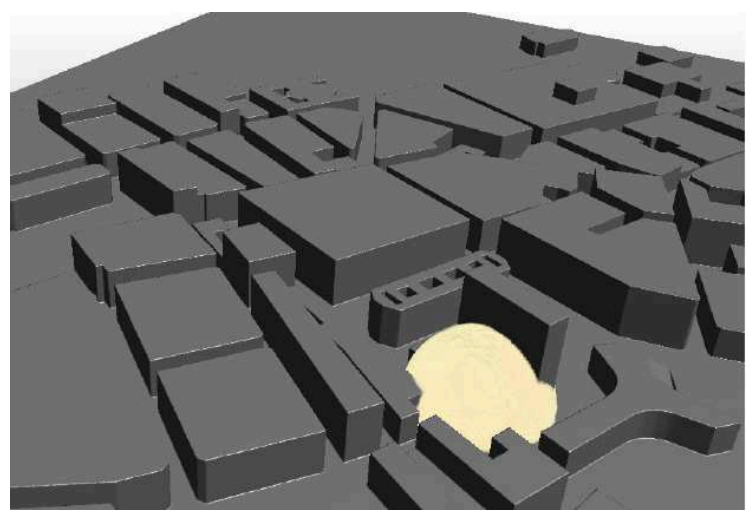

Figure 6a. Initial particle cloud estimated from footage from surveillance cameras following the Oslo bombing July 22, $2011^{77}$.

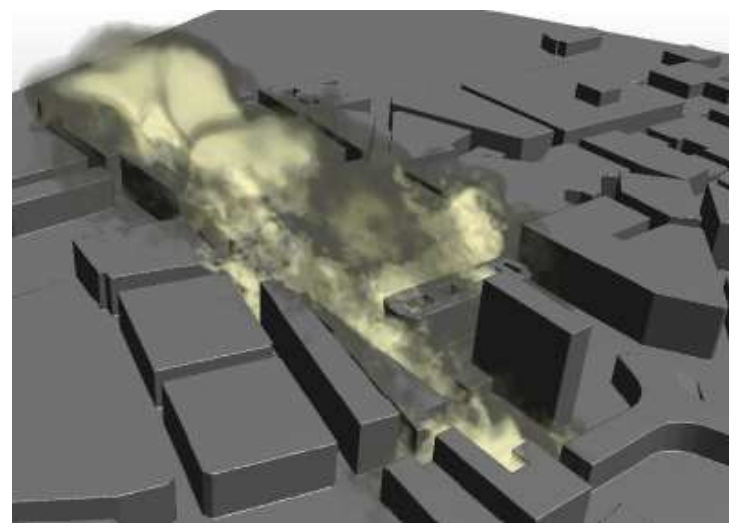

Figure 6b. Simulated particle cloud 55 seconds after the initial release.

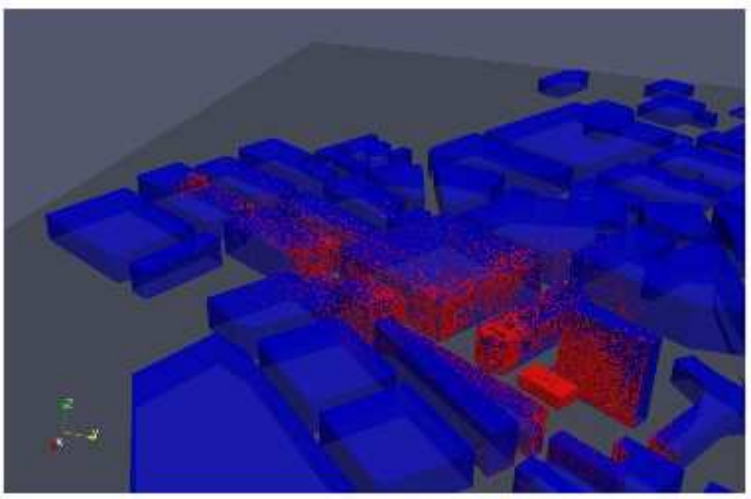

Figure 6c: Simulated bomb residue particles deposited on building surfaces in central Oslo. Ground deposition not shown.

\section{Summary}

Evidently a theoretical platform for residue distribution exists in the published literature; however the models postulated are only vaguely defined with little empirical data incorporated to validate them. In order to develop the theoretical aspects of this subject, a detailed analysis of all empirical data produced, in a systematic fashion is required. Firstly, the formation, or survival, of undetonated residue particles from the main explosive charges requires assessment - only with an informed understanding of the most likely mechanism of formation can the subsequent dispersal and distribution be fully recognised and explained. Experimental assessments could be designed to examine the movement of particles at the explosive charge boundary during detonation in order to investigate the theory of particle spallation from the charge surface during shockwave reflection at the boundary for example. Secondly, in order to strengthen the theoretical models for residue distribution, the experimental work conducted to date, both analysing perpendicular and ground sampling sites needs to be developed. Experiments which incorporate both types of sampling positions at numerous sites are ideally required, along with the detonation of further explosive charges, including improvised or home-made mixtures as well as military explosives. Since very little, if any, explosive residue remains following the detonations of peroxide based explosives, for example, understanding the potential residue distribution patterns of these types of explosive also would be of great value to scene investigators. Additionally, experiments which measure the distribution of residue from confined charges (by sampling for the 'free-moving' residue as well as mapping out the fragment distribution of the confinement) would add greatly to this field. Finally, the simulation efforts within this domain appear promising and offer a method of overcoming experimental impracticalities; nonetheless it is necessary to consolidate the modelling by coupling it with useful empirical data in order to ensure the generation of accurate and reliable models; without which they remain hypothetical.

\section{Conclusions}

With the criminal uses of explosives, potential environmental effects of their use during military training, and the risk of dirty bombs becoming ever stronger, it is imperative to have a comprehensive understanding of the movement of explosive residue particles in order to develop the most efficient and effective methods for collection, analysis, and interpretation of these materials. The main conclusions from this review are:

- Mechanisms of undetonated explosive residue formation following a high order detonation are theoretically governed by chemical and physical aspects of explosion such as the VOD of the explosive charge or reflection of the shockwave at the charge boundary. However little empirical evidence has been produced to support any such notion.

- The distribution patterns of these residues from the point of detonation are postulated to be based on models such as the inverse square model. Influential factors such as the explosive charge and fireball size are acknowledged but not incorporated fully into theoretical models. 
- Experimental work in the forensic, military and environmental disciplines has established trends in reside distribution; principally that of decreasing residue concentration with increasing distance, however directional biases are apparent and these patterns are not the only ones found. Further empirical validation is required to build on the preliminary datasets in the literature to establish dispersal trends for different explosives.

- Simulation of explosive residue distribution using computational modelling is capable of mapping out particle concentrations in built environments and has clear advantages over experimental capabilities where such experiments are not feasible. The models used however still need to be validated with empirical data.

\section{Acknowledgements}

The Engineering and Physical Sciences Research Council is acknowledged for funding the project under which this review was conducted. The authors would also like to acknowledge Dr Magnus Vartdal at FFI for discussions that helped improve the paper and Dr Ruth Morgan at the UCL Centre for the Forensic Sciences. Three anonymous reviewers are also thanked for their comments, which improved this review.

\section{Notes and references}

${ }^{a}$ Christopher Ingold Laboratories, Department of Chemistry, University College London, 20 Gordon Street, WC1H 0AJ, UK.

${ }^{b}$ Department of Security and Crime Science, University College London, 35 Tavistock Square, London, WC1H 9EZ, UK

${ }^{c}$ Centre for Defence Chemistry, Cranfield University, Shrivenham, Swindon, SN6 8LA, UK

${ }^{d}$ Protection and Societal Security Division, Norwegian Defence Research Establishment (FFI), Kjeller, Norway

1. Strobel, R. 'Recovery of Material from the Scene of an Explosion and its Subsequent Forensic Laboratory Examination - A Team Approach in Forensic Investigation of Explosions. (Beveridge, A. Ed.) pp. 113148. Taylor and Francis Ltd. (1998).

2. Zitrin S. \& Yinon, J. Modern Methods and Applications in Analysis of Explosives. Wiley (1996).

3. Yallop, H. J. Explosion Investigation. Forensic Science Society and Scottish Academic Press Ltd. (1980).

4. Zonderman, J. Beyond the Crime Lab: The New Science of Investigation. John Wiley and Sons (1998).

5. Technical Working Group for Bombing Scene Investigation. A Guide for Explosion and Bombing Scene Investigation. National Institute of Justice Research report, Office of Justcie Programs (2000).

6. Hoffman, C.M., \& Byall, E. B. 'Identification of Explosive Residues in Bomb Scene Investigations'. J. Forensic Sci. 19, pp. 54-63 (1974).

7. Lancaster, S. L., Marshall, M. \& Oxley, J. C. 'Explosion Debris: Laboratory Analysis of', in Wiley Encyclopaedia of Forensic Science. (Jamieson, A. \& Moenssens, A. Eds.) pp. 1028-1060, Wiley, (2009).

8. Lane, B. The Encyclopaedia of Forensic Science. Headline Book Publishing (1993).

9. Nickell, J. and Fischer, J. F. Crime Science Methods of Forensic Detection. University Press of Kentucky (1999).

10. Jackson, A. \& Jackson, J. M. Forensic Science. pp. 326 -343 Pearson Education Limited (2008).

11. Siegel, J. A., Saukko, P. J. \& Knupfer, G. C. Encyclopaedia of Forensic Sciences: Volume 2. (Academic Press, 2000).

12. Houck, M. M. 'Fires and Explosions', in Fundamentals of Forensic Science. (Houck, M. M. \& Siegel, J. J. Eds.) pp. 431 - 471, Elsevier (2010).

13. Walls, H. J. Forensic Science. Sweet and Maxwell, London (1974).
14. Giles, G. 'Green Explosives: Collateral Damage', Nature, 427, pp. 580581 (2004)

15. Adam, D., Karaghiosoff, K., Klapotke, T. M., Holl, G. \& Kaiser, M. 'Triazidotrinitro Benzene: 1,3,5-(N3)3-2,4,6-(NO2)3C6', Propellants, Explos. Pyrotech. 27, pp. 7-11 (2002)

16. Huynh, M. V., Hiskey, M. A., Meyer, T. J. \& Wetzler, M. 'Green primaries: Environmentally friendly energetic complexes'. Proc. Natl. Acad. Sci. U. S. A,. 103, pp. 5409-5412 (2006).

17. Varga, R. \& Ulbrich, P. 'Some Experience with Trace Analysis of PostExplosion Residues', Academic and Applied Research in Military Science, 3, pp. 633-646 (2004).

18. Kelleher, J. D. 'Explosives Residue: Origin and Distribution'. Forensic Science Communications, 4, (2002). Available online: http://www.fbi.gov/about-us/lab/forensic-sciencecommunications/fsc/april2002/kelleher.htm

19. Akhavan, J. The Chemistry of Explosives. Royal Society of Chemistry (2004).

20. Field, J. E. 'Hot Spot Ignition Mechanisms for Explosives'. Am. Chem. Soc. 25, pp. 489-496 (1992).

21. Bowden, F. P. \& Yoffe, Y. D. Initiation and Growth of Explosion in Liquids and Solids. Cambridge University Press (1952).

22. Kubota, N. Propellants and Explosives: Thermochemical Aspects of Combustion. $2^{\text {nd }}$ Edition. Wiley-VCH. Weinheim, Germany (2007)

23. Kosanke, K. L., Dujay, R. C. \& Kosanke, B. J. 'Pyrotechnic reaction residue particle analysis'. J. Forensic Sci. 51, pp. 296-302 (2006).

24. Meyer, R., Kohler, J. \& Homburg, A. Explosives. $6^{\text {th }}$ Edition. WileyVCH, Weinheim, Germany (2007).

25. Beveridge, A. Forensic Investigations of Explosions. Taylor and Francis, London (1998).

26. Cooper, P. W. \& Kurowski, S. R. Introduction to the Technology of Explosives. (Wiley-VCH, 1996)

27. Davis, W. C. 'Chapter 3: Shock Waves, Rarefaction Waves, Equations of State', in Explosive Effects and Applications. (Zukas, J. A \& Walters, W. P. Eds.) pp. 47-114, Springer, New York, USA (2003).

28. Keshavarz, M. H. 'Chapter 9: A Simple Theoretical Prediction of Detonation Velocities of Non-Ideal Explosives only from Elemental Composition' in New Res. Hazard. Mater. (Warey, P. B. Ed.) pp. 293310, NOVA Science Publishers, Inc. (2007).

29. Cooper, P. W. 'Chapter 4: Introduction to Detonation Physics' in Explosive Effects and Applications. (Zukas, J. A. \& Walters, W. P. Eds.) pp. 115 - 136, Springer, New York, USA (2003).

30. Van der Steen, A. C. \& Kodde, H. H. 'Detonation Velocities of the Non-Ideal Explosive Ammonium Nitrate'. Propellants, Explos. Pyrotech. 15, pp. 58-61 (1990).

31. Jones, G. E., Kennedy, J. E. \& Bertholf, L. D. 'Ballistics Calculations of R. W. Gurney'. Am. J. Phys. 48, pp. 264-269 (1980).

32. Gurney, R. W. The Initial Velocities of Fragments from Bombs, Shell, Grenades, Aberdeen Proving Ground, Ballistics Research Laboratories, Report No. 405. (1943).

33. Kennedy, J. E. Gurney Energy of Explosives: Estimation of the Velocity and Impulse Imparted to Driven Metal. Sandia Laboratories, SC-RR70-790 (1970).

34. Zaker, T. A. Fragment and Debris Hazards. Department of Defence Explosives Safety Board, Report No. DDESB-TP-12, Washington D.C. (1975).

35. Di Baldassare, G., Ripani, L. \& Silvestrini, M. 'Esplosioni: Utilizzo di Modelli per la Previsione Degli Effetti e per L'investigazione', Quad. Di Sci. Tec. pp. 3-28 (2005).

36. Bishop, R. H. Maximum Missile Ranges from Cased Explosive Charges. Sandia Corporation, SC-4205-TR (1958).

37. Baker, W. E., Kulesz, J. J., Ricker, R. E., Westine, P. S., Parr, V. B., Vargas, L. M. \& Mosely, P. K. Workbook for Estimating Effects of Accidental Explosions in Propellant Ground Handling and Transport Systems. NASA Contractor Report No. 3023 (1978).

38. Dean, R. \& Edwards, M. R. 'Fragment Distribution as an Aid to Forensic Failure Investigations at the Scene of Explosions', Pract. Fail. Anal. 2, pp. 33-40 (2002).

39. Oxley, J. C., Smith, J. L., Resende, E., Rogers, E., Strobel, R. A. \& Bender, E. C. 'Improvised Explosive Devices: Pipe Bombs', $J$. Forensic Sci. 46, pp. 510-534 (2001).

40. Tardif, H. \& Sterling, T. S. 'Explosively Produced Fractures and Fragments in Forensic Investigations'. J. Forensic Sci. 12, pp. 247-272 (1967). 
41. Mott, N. F. 'Fragmentation of Shell Cases', Proc. R. Soc. A, 189, pp. 300-308 (1947).

42. Held, M. 'Chapter 8: Fragmentation Warheads,' in Tactical Missile Warheads. (Carleone, J. Ed.) American Institute of Aeronautics and Astronautics, Inc., Washington D.C. (1993).

43. Monsfield, A. M., Marshall, M., Walker, C. L. \& Hubbard, P. 'Physical and Chemical Evidence Remaining After the Explosion of Large Improvised Bombs. Part 3: Firings of Calcium Carbonate Ammonium Nitrate / Sugar'. J. Forensic Sci. 46, pp. 535-548 (2001).

44. Walsh, M. E. 'Determination of nitroaromatic, nitromine, and nitrate ester explosives in soil by gas chromatography and an electron capture detector'. Talanta, 54, pp. 427-438 (2001).

45. Irwin, A. 'Gas chromatography with chemiluminescence detection (GC/TEA)', in 'Proc. from Work. Explos. Trace Anal. Methods', (Philips, S. A. \& Hiley, R.) Science and Justice, 39, pp. 261-268 (1999)

46. Chen, W., Hou, K., Xiong, X., Jiang, Y., Zhao, W., Hua, L., Chen, P., Xie, Y., Wnag, Z. \& Li, H. 'Non-contact halogen lamp heating assisted LTP ionization miniature rectilinear ion trap: a platform for rapid, onsite explosives analysis'. Analyst, 138, pp. 5068-5073 (2013).

47. Nuntawong, N., Eiamchai, P., Limwichean, S., Wong-ek, B., Horprathum, M., Patthanasettakul, V., Nakngoenthong, S. \& Chindaudom, P. 'Trace detection of perchlorate in industrial-grade emulsion explosive with portable surface-enhanced Raman spectroscopy'. Forensic Sci. Int. 233, pp. 174-178 (2013).

48. Ceco, E., Onnerud, H., Menning, D., Gilljam, J. L., Baath, P. \& Ostmark, H. 'Stand-off imaging Raman spectroscopy for forensic analysis of post-blast scenes: trace detection of ammonium nitrate and 2,4,6-trinitrotoluene'. in Proc. SPIE 9073, Chem. Biol. Radiol. Nucl. Explos. Sens. XV, doi:10.1117/12.2049909

49. Klapec, D. J. \& Czarnopys, G. 'Analysis and Detection of Explosive Residues. Review: 2010 to 2013', in 17th Interpol Int. Forensic Sci. Manag. Symp. (Daéid, N. N. Ed.) pp. 280-435 (2013).

50. Noon, R. Engineering Analysis of Fires and Explosions. CRC Press, Boca Raton, Florida (1995).

51. DeTata, D. A., Collins, P. A. \& McKinley, A. J. 'A comparison of common swabbing materials for the recovery of organic and inorganic explosive residues', J. Forensic Sci., 58, pp. 757- 763 (2013).

52. DeTata, D. A. Collins, P. A. \& McKinley, A. J. 'A comparison of solvent extract cleanup procedures in the analysis of organic explosives'. J. Forensic Sci. 58, pp. 500-507 (2013).

53. Song-im, N., Benson, S. \& Lennard, C. 'Evaluation of different sampling media for their potential use as a combined swab for the collection of both organic and inorganic explosive residues'. Forensic Sci. Int. 222, pp. 102-10 (2012).

54. Kolla, P. \& Sprunkel, A. 'Identification of Dynamite Explosives in Post Explosion Residues'. J. Forensic Sci. 40, pp. 406-411 (1995).

55. Committee on Marking, Rendering Inert, and Licensing of Explosive Materials, Marking, Rendering Inert, and Licensing of Explosive Materials Interim Report, Board on Chemical Sciences and Technology, Commission on Physical Sciences, Mathematics, and Applications, National Research Council, National Academy Press, Washington, D.C. (1997).

56. Office of Technology Assessment, Taggants in Explosives. Government Printing Office, Washington D.C. (1980).

57. Rouhi, M. A. 'Government, Industry Efforts Yield Array of Tools To Combat Terrorism,' Chemical \& Engineering News. July 24, pp. 10-19 and 'How One Chemist's Outrage Sparked a Counterterrorism Invention,' Chemical \& Engineering News, July 24, pp. 13 (1995).

58. Department of Treasury, Bureau of Acohol, Tobacco and Firearms, in Prelim. Proc. Of Int. Explos. Symp. Fairfax, VA. Government Printing Office (1995)

59. Scharer, J. 'Switzerland's Explosives Identification Program'. in Proc. Int. Explos. Symp. Government Printing Office (1995).

60. Mayersak, R. J. 'A Technical Approach to Marking Explosives, Propellants and Precursor Chemicals,' Naval Surface Warfare Center, Indian Head Div Md Ordnance Environmental Support Office(1998).

61. National Research Council. Containing the Threat from Illegal Bombings: An Integrated National Strategy for Marking, Tagging, Rendering Inert, and Licensing Explosives and Their Precursors. Washington, DC: The National Academies Press (1998).

62. Kirkendall, T., Baker, J., Barnes, J. H., Lewis, C. \& Wheeler, M. 'Lanthanide Taggants for Characterizing the Explosive Blast Radius of
Homemade Explosive Mixtures', Poster Presentation in Pittcon, Philadelphia, PA (2013).

63. Phillips, S. A., Lowe, A., Marshall, M., Hubbard, P., Burmeister, S. G. \& Williams, D. R. 'Physical and Chemical Evidence Remaining after the Explosion of Large Improvised Bombs. Part 1: Firings of Ammonium Nitrate/sugar and Urea Nitrate,' J. Forensic Sci. 45, pp. 324-32 (2000).

64. Cullum, H., Lowe, A., Marshall, M. \& Hubbard, P. 'Physical and Chemical Evidence Remaining after the Explosion of Large Improvised Bombs. Part 2: Firings of Calcium Ammonium Nitrate/Sugar Mixtures', J. Forensic Sci. 45, pp. 333-48 (2000).

65. Jones, L., Marshall, M. 'Chapter 9: Explosions' in Crime Scene to Court: The Essentials of Forensic Science. $2^{\text {nd }}$ Edition (White, P. C. Ed.) Royal Society of Chemistry (2004).

66. Abdul-Karim, N., Morgan, R., Binions, R., Temple, T. \& Harrison, K. 'Spatial Distribution of Post-Blast RDX Residue: Forensic Implications'. J. Forensic Sci., 58, pp. 365-71 (2012).

67. Jenkins, T. F., Hewit, A.D., Walsh, M. E., Ranney, T. E., Ramsey, C. A., Grant, C. L. \& Bjella, K. L. Representative Sampling for Energetic Compounds at Military Training Ranges.' Environ. Forensics, 6, pp. 45-55 (2005).

68. Brannon, J. M. Jenkins, T. F., Parker, L. V., Deliman, P., Gerlad, J. A., Ruiz, C., Porter, B. \& Dvais, W. M. Procedures for Determining Integrity of UXO and Explosives Soil Contamination at Firing Ranges. Prepared for Headquarters, US Army Corps of Engineers, ERDC; TR00-4 (2000).

69. Walsh, M. E., Collins, C. M., Racine, C. H., Jenkins, T. F., Gelvin, A. B. \& Ranney, T. A. Sampling for Explosives Residues at Fort Greely, Alaska Reconnaissance Visit. US Army Corps of Engineers, ERDC/CRREL TR-01-15 (2000).

70. Pennington, J.C., Silverblatt, B., Poe, K., Hayes, C.A. \& Yost, S. 'Explosive Residues From Low Order Detonations of Heavy Artillery and Mortar Rounds'. Soil Sediment Contam. An Int. J. 17, pp. 533-546 (2008).

71. Penningon, J.C., Hayes, C.A., Yost, S., Crutcher, T.A., Berry, T.A., Clarke, J.U. \& Bishop, M. J. 'Explosive Residues from Blow in Place Detonations of Artillery Munitions'. Soil Sediment Contam. An Int. J. 17, pp. 163-180 (2008).

72. Lewis, J. Thiboutot, S. Ampleman, G. Brochu, S. Ranney, T. \& Taylor, S. Open Detonation of Military Munitions on Snow: An Investigation of the Quantities of Energetic Materials Produced. RDDC - DRDC, Valcartier, Canada (2002).

73. Jenkins, T. F., Ranney, T. A., Miyares, P. H., Collins, N. H. \& Hewitt, A. D. Use of Surface Snow Sampling to Estmate the Quantity of Explosive Residues Resuting from Landmine Detonations. ERDC/CRREL TR-00-12 (2000).

74. Hewitt, A. D., Jenkins, T. F., Walsh, M. E., Walsh, M. R. \& Taylor, S. 'RDX and TNT residues from live-fire and blow-in-place detonations'. Chemosphere, 61, pp. 888-894 (2005).

75. Taylor, S., Hewitt, A., Lever, J., Hayes, C., Perovich, L., Thorne, P. \& Daghlian, C. 'TNT Particle Size Distributions from Detonated 155-mm Howitzer Rounds', Chemosphere 55, pp. 357-67 (2004).

76. Taylor, S., Campbell, E., Perovich, L., Lever, J. \& Pennington, J. 'Characteristics of Composition B Particles from Blow-in-Place Detonations'. Chemosphere 65, pp. 1405-13 (2006).

77. Wingstedt, E. M. M., Fossum, H. E. \& Pettersson Reif, B. A. Simulation of Bomb Residue Deposition Following the Oslo Bombing July 22, 2011, FFI Rapport 2012/01836, ISBN 978-82-464-2176-6. (2012)

78. Pennington, J. C., T. F. Jenkins, G. Ampleman, S. Thiboutot, J. M. Brannon, A. D. Hewitt, J. Lewis, S. Brochu, E. Diaz, M. R. Walsh, M. E. Walsh, S. Taylor, J. C. Lynch, J. Clausen, T. A. Ranney, C. A. Ramsey, C. A. Hayes, C. L. Grant, C. M. Collins, S. R. Bigl, S. L. Yost, $\&$ K. Dontsova. Distribution and fate of energetics on DoD test and training ranges: Final Report. ERDC TR-06-13. Vicksburg, Miss: U.S. Army Engineer Research and Development Center (2006).

79. Environmental Protection Agency, USA. Method 8330A Nitroaromatics and Nitramines by High Performance Liquid Chromatography (HPLC) (2007). Available online: http://www.epa.gov/osw/hazard/testmethods/sw846/pdfs/8330a.pdf

80. Braithwaite, M. \& Allan, N. L. 'Thermodynamic Representations for Solid Products in Ideal Detonation Predictions'. in 12th Int. Symp. Detonation, San Diego, ONR(2002). 
81. Ngo, T., Mendis, P., Gupta, A. \& Ramsay, J.'Blast Loading and Blast Effects on Structures: An Overview,' Electronic Journal of Structural Engineering, Special Issue: Loading on Structures, pp. 76-91 (2007).

82. Bloom, S. G. Models for Close-In, Atomspheric Dispersion, Explosive Releases, and Particle Deposition. Oak Ridge National Laboratory, ORNL/TM-12452 (1993).

83. Ayer, J. E., Clark, A. T., Loysen, P., Ballinger, M. Y., Mishima, J., Owczarski, P. C., Gregory, W. S. \& Nichols, B. D. Nuclear Fuel Cycle Facility Accident Analysis Handbook. NUREG 1320, US Nuclear Regulatory Commission, Office of Nuclear Material Safety and Safeguards, Washington D. C. (1988).

84. Deaves, D. M. \& Hebden, C. R. Aspects of Dispersion Following an Explosive Release. UK Atmospheric Dispersion Modelling Liaison Committee (2004).

85. Walter, H. Handling "Dirty Bomb"-Scenarios with the Lagrangian Particle Model Lasair. Hrvat. meteorološki časopis 43, pp. 230-234 (2008).

86. Il'nn, V. V., Rybakov, A.P. \& Kozlov, V. V. 'Mathematical Model of Dispersion of Explosive Products During the Exit of Oblique Denotation Wave on the Free'. Investigated in Russia (English) pp. 1538-1545 (2006).

87. Taylor, G.I. 'The Dynamics of the Combustion Products behind Plane and Spherical Detonation Fronts in Explosives' in Proceedings of the Royal Society of London. Series A, Mathematical, Physical and Engineering Sciences, 200, pp. 235-247, (1950).

88. Kuhl, A.L., Bell, J.B., Beckner, V.E. \& Reichenbach, H. 'Gasdynamic model of turbulent combustion in TNT explosions'. Proceedings of the Combustion Institute, 33, pp. 2177-2185 (2010).

89. Lele, S. K. 'Compressible Effects on Turbulence', Annual Review of Fluid Mechanics, 26, pp. 211 - 253. (1994).

90. Brouillette, M.'The Richtmyer-Meshkov instability'. Annual Review of Fluid Mechanics, 34, pp. 445-468, (2002).

91. Pierce, C. D. \& Moin, P. 'Progress-variable approach for large-eddy simulation of non-premixed turbulent combustion', Journal of Fluid Mechanics, 504, pp. 73-97. (2004).

92. Balakrishnan, K. On the high fidelity simulation of chemical explosions and their interaction with solid particle clouds. PhD thesis, Georgia Institute of Technology (2010).

93. Zhang, F., Frost, D.L., Thibault, P.A. \& Murray, S. B. 'Explosive dispersal of solid particles', Shock Waves 10, pp.431-443 (2001).

94. Lanovets, V.S., Levich, V.A., Rogov, N.K., Tunik, Yu.V. \& Shamshev, K. N. 'Dispersion of the detonation products of a condensed explosive with solid inclusions'. Fiz. Goreniya i Vzryva 29, pp. 88-92 (1992).

95. Gottiparthi, K. C., Schulz, J. C. \& Menon, S. 'On the neutralization of bacterial spores in post-detonation flows'. Shock Waves, 24, pp. 455466. (2014).

96. Kuhl, A.L., Bell, J.B., Beckner, V.E., Balakrishnan, K. \& Aspden, A.J. 'Spherical combustion clouds in explosions', Shock Waves, 23 pp. 233249 (2013).

97. Balczo, M., Sabastino, S., Franke, J., Grebec, M., Karpinnen, A., Meijer, E., Moussafir, J., Pettersson Reif, B. A., Tinarelli, G. \& Trijssenaar-Buhre, I., 'Background and Justification document, COST Action ES1006 Report (2012)

98. Turner, J. S. 'Buoyant plumes and thermals', Annual Review of Fluid Mechanics, 1, pp. 29-44 (1969).

99. Pope, S. B. Turbulent flows, Cambridge University Press. (2000).

100. Sagaut, P. Large Eddy Simulations for Incompressible Flows - An Introduction, Springer Verlag, New York. (2005).

101. Maxey, M. R. \& Riley, J. J. 'Equation of motion for a small rigid sphere in a nonuniform flow', Physics of Fluids, 26, pp. 883-889 (1983).

102. Johnson, D. L. 'Drag on Nonspherical Objects', Aerosol Science and Technology, 6, pp. 153-161, (1987).

103. Durbin, P. A. \& Pettersson Reif, B. A. Statistical Theory and Modeling for Turbulent Flows. Wiley \& Sons, Winchester. (2010).

104. Guha, A. 'Transport and deposition of particles in turbulent and laminar flow', Annual Review of Fluid Mechanics, 40, pp. 311-341 (2008).

105. Hussein, T., Smolik, J., Kerminen, V.-L. \& Kulmala, M. 'Modeling dry deposition of aerosol particles onto rough surfaces', Aerosol Science and Technology, 46, pp. 44-59 (2012).

106. Boris, J., Patnaik, G., Obenschain, K. \& Moses, A. 'Fast and accurate prediction of windborne contaminant plumes for civil defense in cities', in Fifth International Symposium on Computational Wind Engineering, North Carolina, USA, pp. 23-27, (2010).

107. Williams, M. D., Brown, M. J., Singh, B. \& Boswell, D. QUIC-PLUME Theory Guide, Los Alamos National Laboratories, Report: LA-UR-040561. (2004).

108. Settles, G. S. 'Fluid Mechanics and Homeland Security', Annual Review of Fluid Mechanics, 38, pp. 87 - 110. (2006).

109. Borysiewicz, M. J. \& Borysiewicz, M. A. 'Atmspheric Dispersion Modelling for Emergency Management', in Models and Techniques for Health and Environmental Hazards Assessment and Management, CoE MANHAZ, Institute of Atomic Energy, (2006).

110. Fossum, H. E., Reif, B. A. P., Tutkun, M. \& Gjesdal, T. 'On the Use of Computational Fluid Dynamics to Investigate Aerosol Dispersion in an Industrial Environment: A Case Study,'Boundary-Layer Meteorol. 144, pp. 21-40 (2012).

111. Wingstedt, E. \& Reif, B. A. P. Numerical Simulations of Particle Dispersion in an Urban Area. Norwegian Defence Research Establishment, FFI Rapprt No. 2012/00266 (2012). 
Graphical abstract

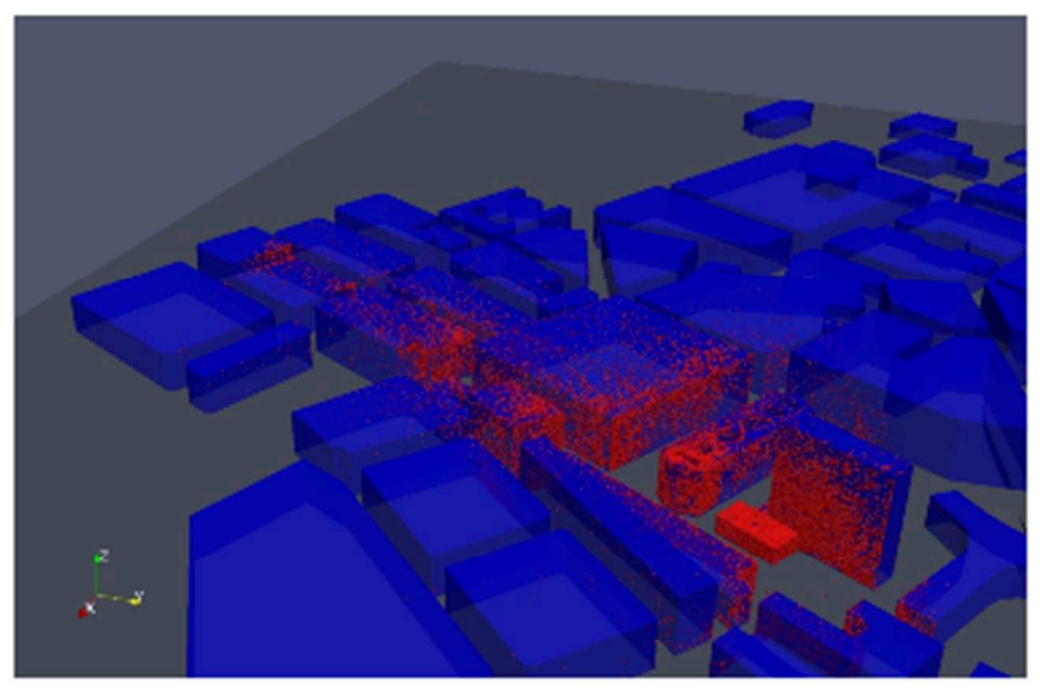

Review of theoretical and experimental research relating to the formation and distribution of postblast explosive residues. 